Federal Reserve Bank of Minneapolis Research Department

\title{
Moving Back Home: Insurance Against Labor Market Risk*
}

\author{
Greg Kaplan
}

Working Paper 677

March 2010

\begin{abstract}
This paper uses an estimated structural model to argue that the option to move in and out of the parental home is an important insurance channel against labor market risk for youths who do not attend college. Using data from the NLSY97, I construct a new monthly panel of parent-youth coresidence outcomes and use it to document an empirical relationship between these movements and individual labor market events. The data is then used to estimate the parameters of a dynamic game between youths and their altruistic parents, featuring coresidence, labor supply and savings decisions. Parents can provide both monetary support through explicit financial transfers, and non-monetary support in the form of shared residence. To account for the data, two types of exogenous shocks are needed. Preference shocks are found to explain most of the cross-section of living arrangements, while labor market shocks account for individual movements in and out of the parental home. I use the model to show that coresidence is a valuable form of insurance, particularly for youths from poorer families. The option to live at home also helps to explain features of aggregate data for low-skilled young workers: their low savings rates and their relatively small consumption responses to labor market shocks. An important implication is that movements in and out of home can reduce the consumption smoothing benefits of social insurance programs.
\end{abstract}

*Kaplan: Federal Reserve Bank of Minneapolis and University of Pennsylvania; email: gregkaplan@nyu.edu. I would like to thank Gianluca Violante, Thomas Sargent and Chris Flinn for the valuable advice they have provided at each stage of this project. This paper is based on Chapter 3 of my PhD dissertation at New York University. I have benefited from participants at seminars and from discussions with people at numerous institutions that are too numerous to mention. The views expressed herein are those of the author and not necessarily those of the Federal Reserve Bank of Minneapolis or the Federal Reserve System. 


\section{Introduction}

For many young people, the passage out of the parental home is a prolonged, transitional phase, in which they alternate between periods of living at home and living independently. ${ }^{1}$ Throughout this phase, young workers face substantial risk in the labor market, yet make minimal use of traditional insurance mechanisms. Low-skilled youths have very little personal wealth, poor access to credit markets, receive only small amounts of direct financial assistance from family members and are often not eligible for benefits from social insurance programs. This paper uses an estimated structural model to account for observed coresidence dynamics and to argue that the option to move in and out of home is a valuable mechanism for insuring against labor market risk, substituting for more traditional insurance channels for young workers.

The use of coresidence as insurance turns out to have important implications. On the positive side, it helps explain otherwise puzzling aspects of youths' economic behavior: their relatively small consumption responses to labor market shocks and their low savings rates. On the normative side, the option to live at home can reduce the consumption smoothing benefits of social insurance programs for youths, suggesting that parental coresidence should be considered when assessing the welfare gains of interventions targeted at young workers.

I start by constructing a new monthly panel dataset of parent-youth coresidence outcomes from the National Longitudinal Survey of Youth 1997 (NLSY97), and use it to document several new facts about the living arrangements of 16 to 23 year-old males who do not go to college. Over this age range, the fraction of youths living independently from their parents increases sharply. However, it is also common for youths to move back home - over $40 \%$ of male youths who lived away from home, were also observed to move back home by age 23. Moreover, there is a direct link between these coresidence movements and labor market events. In Kaplan (2009a) I use the same panel dataset to estimate a series of duration models for movements in and out of home and show that the hazard of moving back home is significantly increased for youths who have recently stopped working. ${ }^{2}$

In light of this evidence, this paper asks three questions (i) To what extent do labor market shocks account for observed patterns of parental coresidence? (ii) What is the value of the option to move in and out of home as a channel of insurance and how does this affect the value of social insurance programs? and (iii) How does coresidence affect young males' savings behavior?

\footnotetext{
${ }^{1}$ A substantial body of anecdotal evidence and reports in the popular press suggest a recent trend in the USA for young people to move back home with their parents after a period of living away from home. This has led to the coining of the term "Boomerang Kids" to describe this group. See Section 2 and Kaplan (2009a) for empirical evidence on the extent of these movements in and out of home for low-skilled youth.

${ }^{2}$ For male youths who do not go to college, the monthly hazard of moving back home is decreased by $34 \%$ if a youth is currently employed, and is increased by $64 \%$ if a youth has recently stopped work. There is also evidence to support a link between parent-youth living arrangements and labor-market outcomes at the aggregate level. Data from the Current Population Survey (CPS) shows that over the last 30 years, the fraction of 16 to 30 year-olds who live with their parents decreases substantially during booms and increases during recessions. Details available from author upon request.
} 
To answer these questions, the paper proceeds by estimating the structural parameters of a dynamic model of labor supply, savings, coresidence and transfer decisions. The structure of the model is a dynamic game between youths and parents. Parents, who are altruistic, can provide both monetary support through explicit financial transfers, and non-pecuniary support, in the form of shared residence. The benefits of shared residence accrue from a reduction in percapita direct housing costs and the availability of public goods inside the parental home. Youths make labor supply and savings decisions, in addition to a choice about whether or not to live with their parents. The model assumes that allocations are given by the unique Markov-perfect equilibrium of this game.

To simultaneously account for the cross-section and time-series dimensions of coresidence and labor market outcomes in the data, the model requires two types of idiosyncratic uncertainty. The first are labor market shocks, that come in the form of job offers, job losses, promotions and changes in productivity. These shocks generate a motive for moving in and out of home, since the housing decision and the labor market are tied together through a budget constraint. The strength of this link depends on the extent to which parents are willing and able to provide direct financial support to youths. In addition, coresidence can be used to insure against the impact of adverse labor market events. The second type of uncertainty is time-varying heterogeneity in youths' relative desire to live away from their parents. This reflects non-labor market events such as finding a partner. The stochastic structure of these shocks is flexible enough so that in principle, all coresidence movements could be generated by preference heterogeneity alone.

Importantly, the model is stylized enough to render structural estimation feasible, with all key parameters pinned down by the available data. The estimated model is able to account for all the salient dimensions of the data. In particular, I am able to identify the unobserved process for preference shocks: these are estimated to be very persistent but with a large amount of cross-sectional heterogeneity. This implies that the extent to which labor-market shocks account for coresidence patterns depends on whether one looks at the cross-section of living arrangements or the within-individual time-series of living arrangements. Whereas only around $15 \%$ of cross-sectional differences are accounted for by labor market outcomes, around $38 \%$ of movements out of and 50\% of movements into the parental home are driven by events in the labor market. This is an important distinction - it implies that the importance of parental coresidence as an insurance channel would be overlooked if one were to restrict attention to cross-sectional regressions or a static structural model.

I then use the model to measure the value of different insurance channels. To do this, I compare the welfare cost of a job loss, expressed in terms of a compensating asset transfer, with the corresponding welfare cost when a particular insurance channel is removed. Measured this way, I find that the option to move in and out of home is valuable for all youths, but particularly so for youths from poor families. This is because parents from the lower part of the income distribution find it more costly to substitute financial transfers for coresidence, when 
the option to move back home is removed. For an average 21 year-old youth from the bottom quartile of the parental income distribution, removal of the option to move back home increases the cost of a job loss by a factor of 6 , compared with a factor of 1.7 for the removal of a simple unemployment insurance system. Conversely, for a youth from the top quartile of the parental distribution, it is financial transfers from parents rather than coresidence that is the most important form of insurance.

Identifying the quantitatively important insurance channels for different subgroups of the population is an important economic goal for at least two reasons. First, the welfare implications of redistributive policy interventions depend crucially on the extent to which policies crowd out private transfers that take place within the family. This paper shows that a key component of these private transfers is coresidence, particularly for low-skilled youths from poor backgrounds. Hence ignoring youths' option to live with their parents can potentially lead to a mistaken assessment of the value of social-insurance programs for young workers. I provide an example of the potential for such effects in Section 6, where I compare the estimated consumption-smoothing benefits of unemployment insurance in an environment where coresidence is ignored, with the estimated benefits when it is modeled. I find that the average drop in consumption due to the loss of a job is increased by 9 percentage points when the level of unemployment benefits is halved and there is no option to live at home. However, when there is an option to live at home, halving the level of unemployment benefits increases this average consumption drop by only 3 percentage points.

Second, studying the way that people smooth shocks sheds light on other aspects of their behavior. For young males, I find this to be especially important with respect to savings. In an influential paper, Hubbard et al. (1995), argued that asset-based, means-tested social insurance, such as that implicit in the US welfare system, can have distortionary effects on savings behavior by discouraging households to accumulate their own precautionary wealth. I find that a similar effect operates for young males through the implicit insurance provided by parents. When support from parents is restricted, asset accumulation increases substantially: without coresidence, average assets are $4 \%$ higher at age 23 than in the baseline environment and $42 \%$ higher without financial transfers. Note that a key contribution of the paper is to highlight the fact that the option to move back home can have important behavioral implications for youths living at home or away, even if they never actually experience such a move. Simply knowing that this opportunity exists, causes youths to modify their savings decisions.

Because it focuses explicitly on the experiences of young men, this paper is admittedly less general than other studies of insurance mechanisms. ${ }^{3}$ However by focusing on a particular group

\footnotetext{
${ }^{3}$ In fact, the estimation restricts attention to youths who do not go to college - around one half of the relevant population. However, this is partly due to limited data availability on coresidence for youths who go to college. Moreover, almost all of the anecdotal evidence in the popular press about movements back home refer to college graduates. Hence the importance of these movements in the current study is likely a lower bound on the importance of allowing for these movements in the entire youth population.
} 
of individuals, the paper makes a point that is overlooked by much of the existing literature on risk-sharing: even if the overall insurability of shocks is the same for different parts of the population, the particular mechanisms that implement this level of consumption smoothing may differ markedly across sub-groups. Moreover, the recent findings in Kaplan and Violante (2009) suggest that young households with low wealth are exactly the group whose insurance mechanisms are least understood. Kaplan and Violante (2009) compute the amount of consumption insurance implicit in a calibrated incomplete-markets lifecycle economy where self-insurance through borrowing and savings is the only private insurance channel. When compared with corresponding estimates from US data in Blundell et al. (2008), it is found to be young households for whom the hypothesis of self-insurance alone is most at odds with the data. This paper argues that parental coresidence is an important component of this additional consumption smoothing.

Connections to Existing Literature The idea that families have an important role to play in smoothing the impact of economic shocks dates back at least as far as the seminal work of Becker (1974) and has been investigated empirically by Hayashi et al. (1996). More recently, a growing body of work has recognized that an important component of intra-family support comes in the form of coresidence. ${ }^{4}$ However, this literature has largely restricted attention to the provision of support after retirement and into old-age. For example, Bethencourt and Rios-Rull (2007) and Pezzin et al. (2007) examine various modes of interaction that determine living arrangements of elderly parents and Costa (1999) studies the interaction between publicassistance programs and these living arrangements.

The existing literature on coresidence at the beginning, rather than the end, of the working life - between young adults and their parents - is largely empirical in nature. It has focussed on comparing the family and individual characteristics of youths living at home versus youths living away from home. In the economics literature, prominent examples are McElroy (1985), Rosenzweig and Wolpin (1993), Rosenzweig and Wolpin (1994), Ermisch and Di Salvo (1997), Ermisch (1999) and Manacorda and Moretti (2006). In the sociology literature examples include Goldscheider and Goldscheider (1999) and Buck and Scott (1993).

By studying the insurance value of parental coresidence, this paper advances a research agenda initiated in part by the findings in Rosenzweig and Wolpin (1993) and Rosenzweig and Wolpin (1994). Their results indicate that coresidence is indeed a common form of assistance provided by parents, and suggest that it should be explicitly considered together with financial transfers when analyzing the nature of parent-youth interactions. Although some of these papers interpret their results within the context of structural models of behavior, few of them estimate structural parameters. ${ }^{5}$ One recent paper that does estimate a structural model of coresidence

\footnotetext{
${ }^{4}$ For an excellent review of work on the various forms of intergenerational ties in economics, sociology and psychology see Bianchi et al. (2006).

${ }^{5}$ Despite the wealth of anecdotal evidence on young people moving back home, this existing empirical literature has largely restricted attention to cross-sectional patterns of coresidence at a point in time, or the first movement out of the parental home. There are very few empirical analyses of movements back home. Two exceptions from
} 
is Sakudo (2007), who investigates the decision to move out of home and get married for young females in Japan.

The work in this paper has strong links to a number of other branches of existing literature. First it is related to the purely theoretical analyses of youth coresidence in Fogli (2004) and Fernandes et al. (2008), that allow for expectations about future outcomes to affect current coresidence decisions. Second, the model builds on a class of models that have incorporated a savings decision into a labor market search setting, pioneered by Danforth (1979), Lentz and Tranaes (2005), Lise (2006) and Low et al. (2007). Third, the paper contributes to a line of literature originally advocated by Deaton and Paxson (1994) that attempts to quantify the extent to which idiosyncratic shocks are insurable. ${ }^{6}$ This paper take a structural approach by explicitly incorporating an as-yet unstudied channel of insurance that is particularly relevant around the time of entry to the labor market. ${ }^{7}$ Finally, it adds to a growing body of evidence that non-labor market shocks are important for understanding economic outcomes at both an individual and aggregate level. ${ }^{8}$

The remainder of the paper proceeds as follows. In Section 2, I describe the data that is used for estimation and highlight key features of the economic environment for low-skilled male youths. Section 3 describes the economic environment the model and Section 4 outlines the structure of a non-cooperative repeated game between youths and parents. In Section 5, I present the estimation strategy, discuss identification of the structural parameters, analyze the fit of the model and evaluate the relative contribution of labor market and preference shocks to coresidence dynamics. In Section 6 I quantify the value of coresidence as an insurance channel and illustrate the interaction of parental support with savings behavior. Section 7 concludes.

\section{Facts About Coresidence and the Labor Market}

In this section I introduce the data that will be used for estimation, and highlight several facts about the economic environment of young males who do not go to college in the USA. ${ }^{9}$

Data Source The data comes from the National Longitudinal Survey of Youth 1997 (NLSY97) and is described in more detail in Appendix A. The NSLY97 is a longitudinal survey of 8,984 in-

the sociology literature are DaVanzo and Goldscheider (1990) who use the 1972 National Longitudinal surveys and Goldscheider and Goldscheider (1999) who use the National Survey of Families and Households. The only study of movements back home at a greater frequency than annual, and that links such movements to contemporaneous events in the labor market is the companion paper Kaplan (2009a).

${ }^{6}$ Other examples include Attanasio and Davis (1996), Hayashi et al. (1996), Storesletten et al. (2004), Krueger and Perri (2006), Blundell et al. (2008) and Kaplan and Violante (2009).

${ }^{7}$ Other examples of papers that study the effect of 'real-world' channels on consumption insurance include Fernández-Villaverde and Krueger (2007) (durable consumption goods), Low (2005), Kaplan (2007) (variable labor supply) and Chatterjee et al. (2007) (bankruptcy protection).

${ }^{8}$ See for example Cubeddu and Rios-Rull (2003).

${ }^{9}$ In a companion paper, Kaplan $(2009 a)$, I provide a more comprehensive empirical analysis. That paper reports the full results from the estimation of various duration models of the hazard of leaving and returning home, and includes an analysis for females. 
dividuals from the cohort born between 1980 and 1984. They have been sampled approximately annually since 1997. The survey contains extensive information on their labor market behavior and educational outcomes, together with detailed information about the youth's family and community background. The questions that make the NLSY97 an ideal data set to study the dynamics of parent-youth living arrangements are a set of retrospective questions about monthly coresidence that were asked in rounds 2-6 (1998-2002). At each interview, these questions asked respondents to list each period of one month or more in which they lived separately from each of their parents. ${ }^{10}$ From these questions, it is possible to reconstruct a monthly panel of parental coresidence outcomes for each respondent, which was then merged with data on educational, labor market and marital histories.

Sample Selection Sample selection poses a challenge for this analysis. First, the fact that the monthly coresidence questions were discontinued in 2002 restricts the ages at which it is possible to observe contemporaneous labor market and coresidence outcomes for youths in the NLSY97. In particular, this means that studying the interaction between labor market dynamics and coresidence dynamics for youths who go to college is not possible. In this paper, I thus focus attention on the population of low-skilled youths who do not attend college. ${ }^{11}$

However, implementing the restriction to the non-college population raises its own challenges. First, for youths in this age group, the decision about whether to attend post-secondary education is almost certainly endogenous with respect to labor market opportunities and coresidence outcomes. Hence, selecting on the basis of observed education choices may introduce non-random selection on unobservable characteristics into the sample. Second, many youths may initially decide to enter the labor market in the years immediately following high school, but may return to education at some point in the future. Moreover, it is common for youths to attend non-traditional part-time colleges, a decision that may also be correlated with labor market opportunities.

My approach is to choose a baseline sample of youths who are never observed to participate in any type of post-secondary education. Choosing a sample of youths for whom we can condition on the decision to not attend college allows the focus to be placed clearly on the interaction between residential movements and labor market events. It seems a natural starting point for understanding the economic implications of coresidence movements for low-skilled youths and avoids the complications that arise from the interaction with college choice.

To address the potential concerns regarding endogeneity of the education decision, I also compare the baseline sample with two alternative samples that implement the restriction to

\footnotetext{
${ }^{10} \mathrm{~A}$ parent is defined in the NLSY97 as a biological, step, adoptive or foster parent. Youths were explicitly asked to ignore periods of temporary separation from their parents due to summer camp. See Appendix A for details.

${ }^{11}$ After 2002 (round 6), the retrospective coresidence questions were replaced with two questions that ask about the month and year that a youth first lived away from his/her parents, and the month and year when he/she returned home for a period of at least three months. It is possible, as the cohort ages, that these questions could also be used to study movements back home for college graduates.
} 
low-skilled youth in different ways. ${ }^{12}$ First, I select on the basis of low test scores, which are a strong predictor of future college participation. Since selection in this sample is based on a purely exogenous variable, and there are no issues of endogeneity of education. Next, I construct a less restrictive sample by only dropping youths who are traditional college participants - those youths who start college immediately after graduating from high school, or within one year of graduating. The purpose of this last sample is to retain youths who may attend college parttime. I find that both of these alternative samples generate statistics that are very similar to the baseline sample, indicating that none of the structural estimation results would be severely affected by selecting low-skilled youths using a different criterion.

The other important selection criteria are as follows. Females are dropped, as are males who ever go to the military or have all parents dead. ${ }^{13}$ A youth is included in the final panel from the first month after he stops attending high school or after he turns 16, whichever is later. Only youths who have non-missing residence data are included in the final sample. The final sample consists of 41, 406 month-youth observations, for 1,613 male youths ranging in age from 16 to 23 . These generate 427 spells back home, where a spell is defined as one that is not left censored. Since the NLSY97 has an oversampling of black and hispanic youths, sample weights are used in all calculations. Table 1 reports the number of respondents lost at each stage of the selection process. Weighted summary statistics for the final sample are shown in Table 2 .

Parental Coresidence Figure 1(a) plots the increase in the fraction of the sample living away from home between ages 16.5 and 22.5. Over these 6 years, this fraction increases roughly linearly from $21 \%$ to $55 \%$, and will presumably continue to increase as the cohort ages. ${ }^{14}$ However, it may take some time to reach 100\%. Evidence from the Consumer Expenditure Survey and the Current Population Survey suggests that for older cohorts, the fraction of males not living with their parents plateaus at $90 \%$ at around age 40 . The fact that even by age 23 nearly half of the subjects are living with their parents, suggests that a substantial fraction of the sample may not move out at all during the sample period. This is correct: Table 2 reports that $47 \%$ of the sample are observed to live at home throughout the whole sample period.

Moving In and Out of Home The main premise of this paper is that for many youths, moving out of home is not a one-way transition. Evidence for this can be found in Figure 1(b).

\footnotetext{
${ }^{12}$ Results are available from the author on request.

${ }^{13}$ Focussing exclusively on males avoids modeling complications due to benefit eligibility for young females. Whereas very few males of this age group receive some form of government support, its it not uncommon that females to receive benefits. Many such benefits are related to early child-bearing and importantly, eligibility for certain benefits is conditioned on residential choices. While this is an interesting feature of the benefit system for females that could be explored in future research, I focus on the simpler case of males in this paper.

${ }^{14}$ It may appear surprising that the fraction living away from home is positive at age 16.5. This is because the selection criteria impose that only youths who have already completed their education are included in the sample. Because the decision to stop school is closely related to the decision to move out of home, a selection effect is introduced, whereby those youths in the sample at ages 16 and 17 are more likely to be living away than other males of that age. These are youths that had already finished school and were living away from home when they entered the sample.
} 
The solid blue line shows the fraction of youths of each age who have ever lived away from home and the dashed red lines shows the corresponding fraction that has ever moved back home. $45 \%$ of all 22.5 year-olds in the sample have moved back home at some point. Of course to move back home, one has to first live away from home, and this number represents $59 \%$ of the corresponding fraction of youths who have ever lived away. Again, the right-censoring of the coresidence panel prevents us from observing how big this fraction becomes as the cohort ages, but a lower bound on the fraction of youths who ever move back home of $45 \%$ is considerably high, and should be taken as evidence that movements back to the parental home are a common occurrence for youths who do not go to college in the USA. ${ }^{15}$

The fact that the NLSY97 allows for monthly coresidence data to be constructed means that it is possible to examine the nature of movements in and out of the parental home in more detail than has been studied in the past. ${ }^{16}$ The average monthly probability of moving back home amongst youths living away from home is $3.1 \%$. The corresponding average monthly probability of moving out of home is $2.9 \%$. These high movement rates further support the notion that there is a strong dynamic component to parent-youth coresidence.

Figure 1(c) reports the Kaplan-Meier estimate of the empirical survival function for spells back home. Overall, spells are fairly long, with a median duration of 12 months back home. However, the survival function also reveals considerable heterogeneity in the duration of spells back home. Some spells are fairly short: $28 \%$ are 6 months or less in duration; yet some spells are very long: $26 \%$ are 2 years or more. Recall that due to the nature of the survey question, a spell is only included if it is longer than 1 month. It is thus likely (although difficult to confirm) that there are numerous extremely short spells back home, of less than one month duration, that are ignored altogether. In addition, a large fraction of spells (59\%) are right censored, which suggests that durations may be even longer than those reported here.

Entering the Labor Market Figures 2(a) and 2(b) show that there is a large amount of non-stationarity in the earnings and employment for young males who do not go to college over this age range. The fraction of youths that are working in a given month increases from around $40 \%$ to around $80 \%$. Average monthly earnings, conditional on working in a given month, approximately doubles, from around $\$ 1,500$ to around $\$ 3,000{ }^{17}$

Unstable Labor Market Young males who do not go to college face considerable instability in the labor market. Figures 2(c) and 2(d) show the monthly separation rate and survival

\footnotetext{
${ }^{15}$ These statistics constitute empirical evidence to support the numerous informal anecdotes in the popular press about youths moving back home. Examples can be found at http://en.wikipedia.org/wiki/Boomerang_Generation.

${ }^{16}$ Having access to monthly data makes it possible to address questions about the length of spells back home, how the hazard of leaving home again changes with the duration of the spell back home and how the hazards of moving in and out of home are affected by recent events in the labor market. This is in contrast with existing empirical studies, which have utilized either annual data or data on single spells away from home. Such studies include DaVanzo and Goldscheider (1990), Goldscheider and Goldscheider (1999), Ermisch and Di Salvo (1997), Ermisch (1999), McElroy (1985), Rosenzweig and Wolpin (1993) and Rosenzweig and Wolpin (1994).

${ }^{17}$ All currency units reported in the paper are in terms of January 2007 dollars.
} 
function for spells out of work. Figure 2(c) suggests that jobs are particularly fragile for this group: the monthly separation rate is around 5\%, which translates to an annual rate of over $40 \%$. Youths also face substantial earnings fluctuations when employed. Conditional on working, the monthly probability of an earnings change - either through a job change, a wage change on the job or a change in hours worked - is around 24\%. In addition, Figure 2(d) reports that spells out of work tend to be fairly long. The median duration out of work is 4 months, with a long right tail. Both a gradual process of attachment to the labor market and high job mobility for young workers are facts that are consistent with evidence from an earlier cohort, documented by Topel and Ward (1992).

Coresidence and the Labor Market Figures 2(e) and 2(f) provide a view of how earnings differ between youths living at home and youths living away. Figure 2(e) plots the average log monthly earnings of youths away (solid blue line) and youths at home (dashed red line) against age. There are three things to note. First, the increase in average earnings over this age range occurs in both residence states. Second, the difference between earnings at home and away, conditional on age, is very small. Conditioning on age is important when making this comparison, since the fact that both earnings and the probability of living away from home increase with age induces a spurious difference in the average earnings of those at home and those away. Third, earnings of youths at home are initially similar to, or slightly above, that of youths away from home, but this gradually reverses as the group ages. This point can be seen more clearly in the Figure 2(f), which plots the away-home difference in average log earnings.

It is important to note that the fact that the earnings of youths at home is very similar to those away from home does not necessarily imply that the labor market is not a driving force behind coresidence outcomes. The facts in Figure 2 are cross-sectional, whereas in Section 5.3 I will use the estimated model to argue that it is primarily coresidence movements that are related to labor market outcomes. To provide some direct evidence for this hypothesis, I calculate the average monthly probabilities of moving in and out of home by labor market status. The monthly probability of moving back home is higher for youths who are not working than for youths who are $(3.7 \%$ compared with $2.8 \%)$. Similarly, the probability of leaving home is higher for working youths than non-working youths (3.0\% compared with 2.6\%). In Kaplan (2009a) I estimate a series of duration models and show that the relationship between labor market events and the probability of moving back home is strong and significant even once other characteristics are controlled for. I find that the monthly hazard of moving back home is $34 \%$ lower when a youth is working and $64 \%$ higher if the youth stopped work in the previous month.

Assets I focus on two measures of wealth: net financial assets and net financial assets plus net value of cars. These measures can be constructed using annual data for a subset of youths from ages 17 to $20 .{ }^{18}$ Figures $3(\mathrm{a})$ and 3(b) show that youths in the sample hold very little

\footnotetext{
${ }^{18}$ See the appendix for further details on the availability of wealth data in the NLSY97 and the construction of asset variables.
} 
wealth. A large proportion of youths actually hold no assets at all. For financial assets, this fraction decreases from $72 \%$ to $41 \%$ between ages 17 and 20 . When cars are included these fractions drop to $53 \%$ and $27 \%$. Nonetheless, for those youths with non-zero wealth, average assets increase modestly between the ages of 17 and 20 - from $\$ 650$ to $\$ 1,600$ for financial assets, and from $\$ 1,750$ to $\$ 4,600$ when cars are included.

Financial Transfers from Parents Figures 3(c) and 3(d) report statistics on the extent of annual financial transfers from parents to youths. ${ }^{19}$ Although around one third of subjects reported receiving financial support from their parents in a given year, the reported amounts are low. Conditional on receiving a positive transfer, the overall mean and median amounts are approximately $\$ 1,100$ and $\$ 470$ respectively. However, it is important to view the data on transfer amounts with caution for two reasons. First, recall bias may lead to substantial under-reporting of cash transfers during a given year. This is particularly true if transfers are made as irregular small amounts over the course of the year, rather than in a single lump sum. Second, it is likely that a large fraction of transfers from parents to children are not made in cash. Transfers often result from either purchasing goods directly (such as meals or clothing) or through in-kind transfers (such as the use of the family car). For these reasons, I focus exclusively on the fraction of youths that receive a transfer, rather than the amount of transfers, when estimating the model, and view the data on transfer amounts as underestimates of true financial transfers.

Summary of Key Facts The facts documented in this section highlight some of the defining features of the economic environment for young males who do not go to college in the USA. We have seen that over the age range 16 to 23: (i) the fraction of youths living away from their parents increases with age; (ii) transitions in and out of the parental home are common; (iii) non-working youths are more likely to move back home than working youths; (iv) employment increases substantially with age, as does earnings when employed; (v) the labor market is unstable and separation rates are high; (vi) the away-home difference in earnings is small and increases with age; (vii) youths hold very small amounts of financial wealth; (viii) around one third of youths receive financial transfers from their parents.

\section{A Model of Coresidence, Labor Supply and Savings}

I now present a model that is rich enough to account for these facts, yet places enough structure on the data to enable estimation of the key parameters governing coresidence, labor supply and transfers decisions. In this section, I outline the physical environment and the set of feasible allocations. $^{20}$

\footnotetext{
${ }^{19}$ See Appendix A for details on the construction of transfer variables.

${ }^{20}$ In Appendix B, I describe a simplified static version of the model which admits a closed-form solution and is useful for demonstrating some of the key mechanisms that are at work.
} 
Demographics Time is discrete and measured in months. I focus on the finite horizon $t=0,1 \ldots T$. The basic unit in the model is a family, which consists of a parent-youth pair. Families are indexed by $j$, and each comprises a parent $(p)$ and a youth $(y)$. In any month, $t$, the family can be in one of two residential states, labelled $r_{j t} \in\{0,1\}$. When $r_{j t}=0$ the youth lives in the parental home and when $r_{j t}=1$ the youth lives in separate housing away from his parents.

Youth Preferences Youths have time-separable, expected-utility preferences, defined over consumption, labor supply and the residence state. Let $U_{j t}^{y}$ denote the period utility for a youth from family $j$ :

$$
U_{j t}^{y}=\frac{\left[c_{j t}^{y(1-\phi)} G^{\phi}\right]^{1-\gamma}}{1-\gamma}-h_{j t} v+r_{j t} z_{j t}
$$

Period utility is additively separable between utility from consumption, labor supply and direct utility from independence. There are two types of consumption goods. $c_{j t}^{y}$ is the youth's consumption of a private good, enjoyed exclusively by the youth. $G=g_{j t}^{y}+\left(1-r_{j t}\right) g_{j t}^{p}$ is total consumption of a locally public good inside the home. It consists of the youth's own purchases of the good, $g_{j t}^{y}$, as well as public consumption purchased by the parent that is available inside the parental home, $g_{j t}^{p}$. Of course, the youth only has access to this second quantity of the public good if he lives at home, i.e. $r_{j t}=0$.

In reality, most types of consumption fall somewhere in between these two extremes: a completely non-rival and non-excludable good $(g)$ and a fully private good $(c)$. The extent to which there exists economies of scale in the parental home, or in other words, the extent to which most consumption is like $g$ rather than $c$ is a key determinant of the value of coresidence and the impact of coresidence on behavior. The Cobb-Douglas specification allows for a parameter $\phi$ (the weight on public goods in the utility function) that indexes this extent. When $\phi=1$, only public goods are consumed and there are full economies of scale, when $\phi=0$, all consumption is private and there are no economies of scale. In section 5.1, I use data on consumption equivalence scales to calibrate a value for $\phi .{ }^{21} \mathrm{I}$ assume a CRRA utility function over the composite consumption good, with risk aversion $\gamma$.

The value of living away from home, $z_{j t}$, is stochastic and differs across youths. In any month, a youth can be either working, $h_{j t}=1$, or not working, $h_{j t}=0$. The disutility of working is constant and fixed at $v$. Lifetime utility for a youth is given by

$$
V_{0}^{y}=E_{0}\left\{\sum_{t=0}^{T} \beta^{t} U_{j t}^{y}+\beta^{T+1} V_{T+1}^{y}\right\}
$$

where $V_{T+1}^{y}$ is a terminal value function described below.

\footnotetext{
${ }^{21}$ In a previous version of this paper, Kaplan (2009b), I specified the parameter $\phi$ as part of the budget constraint, rather than as a preference parameter. In that version, I estimated the model under the two extreme (and unrealistic) cases of no economies of scale $(\phi=0)$ and full economies of scale $(\phi=1)$. In these two extreme cases, that formulation is equivalent to the one adopted here.
} 
Preference shocks, $z_{j t}$, are assumed to follow a discrete-state Markov process in logs whose variance, $\sigma_{z}^{2}$, and auto-correlation, $\rho_{z}$, are constant with age. The preference shocks play an important role in the model and should be interpreted as a reduced-form way of capturing the effects of non-labor market heterogeneity in the relative preference for living away from home. Such shocks may include the formation and dissolution of cohabiting relationships, peer effects and changes in the demographic structure of the parental home. In reality, these effects are likely to exhibit an increasing trend with age, making living away from home an increasingly attractive option for young adults as they get older. For example, independence from one's parents is itself something that becomes more attractive as youths move towards adulthood. To capture this feature of coresidence, the mean relative preference for living away from home (in levels), $E\left[z_{t}\right]=\alpha_{z}+\beta_{z} t$, is allowed to increase exogenously according to a linear trend.

It will become apparent that the model features a number of endogenous mechanisms for generating the observed increase in the fraction of youths living away from home between the ages of 16 and 23, all related to the labor market experience of youths. ${ }^{22}$ If $E\left[z_{t}\right]$ were assumed to remain constant with age, the model would risk assigning an overly important role to the labor market in determining coresidence patterns. By allowing for flexibility in the mean growth, variance and autocorrelation of $z$, the model is such that in principle, either labor market or nonlabor market factors could be the primary driver of coresidence outcomes. The features of the data that help identify these parameters, and hence distinguish between these two hypotheses, are discussed in Section 5.2.

Parent Preferences Parents have time-separable expected utility preferences and are altruistic towards their children. They have direct preferences over their own private consumption, $c_{j t}^{p}$, and public consumption, $g_{j t}^{p}$ :

$$
U_{j t}^{p}=\frac{\left[c_{j t}^{p(1-\phi)} g_{j t}^{p \phi}\right]}{1-\gamma}
$$

Their total utility, ${ }^{23} V_{0}^{p}$, consists of their direct utility, $\widetilde{V}_{0}^{p}$, plus the utility of their child, $V_{0}^{y}$, weighted with an altruism factor, $\eta \geq 0$ :

$$
\begin{aligned}
& V_{0}^{p}=\widetilde{V}_{0}^{p}+\eta V_{0}^{y} \\
& \widetilde{V}_{0}^{p}=E_{0}\left\{\sum_{t=0}^{T} \beta^{t} U_{j t}^{p}+\beta^{T+1} V_{T+1}^{p}\right\}
\end{aligned}
$$

This form of one-sided altruism has a long history in the modeling of parent-child interactions and has a number of implications for behavior. ${ }^{24}$ First, altruism is the mechanism that is used

\footnotetext{
${ }^{22}$ These mechanisms include: (i) an increasing probability of working; (ii) an increasing earnings profile conditional on working; and (iii) asset accumulation.

${ }^{23}$ Note that this formulation of preferences implies that parents do not get utility from public consumption purchased by the youth $\left(g_{j t}^{y}\right)$ when the youth lives at home. This asymmetry is unlikely to have any meaningful effect on allocations because in most cases the youth does not make additional purchases of public consumption when living at home.

${ }^{24}$ See for example, Altonji et al. (1997) and references therein.
} 
to generate financial transfers from parental to youths. Second, note that when $z_{j t}>0$, both parents and youths have a preference for the youth to live away. However, since in general $\eta<1$, parents have a weaker direct preference for youths to live away than do youths themselves. This conflict may manifest itself in the form of multiple equilibria of a simultaneous-move version of the game described in Section 4, and motivates the need to specify an appropriate timing protocol for the game. Altruism also implies that parents have a stronger preference for youths to work at a given wage, generating a second form of conflict. Both forms of conflict can generate inefficiencies, which are discussed in Appendix D. ${ }^{25}$

Youth Budget Constraint In each period, a youth can be in one of two labor market states: employed $\left(h_{j t}=1\right)$ or non-employed $\left(h_{j t}=0\right)$. An employed youth earns an idiosyncratic monthly wage $w_{j t}$, which is the outcome of a stochastic process, outlined in the section below on the labor market. A non-employed youth without an offer to work receives an exogenous amount b. This should be interpreted as the benefit from a simple public unemployment insurance program. Labor income taxes are levied according to the function $\tau{ }^{26}$

Youths can use their income to purchase private and public consumption goods, $c_{j t}^{y}$ and $g_{j t}^{y}$, and to invest in a risk-free asset, $a_{j, t+1}$ which earns interest at a gross rate $R .^{27}$ In addition, a youth may receive a transfer $T_{j t} \geq 0$ from his parents. There is a per-period fixed monthly cost of housing, $\chi$, payable by youths living away from home and a fixed cost $\kappa$ of moving out of home. The per-period cost is meant to capture both direct housing costs such as rent and mortgage payments, as well as indirect costs such as gas and electricity bills. The fixed cost of moving out is intended to capture direct moving costs as well as indirect costs that may include purchases of new furniture and other durable consumption goods. There is no fixed cost for moving back home. The youth budget constraint is hence given by:

$$
\begin{array}{llll}
\text { Home: } & c_{j t}^{y}+g_{j t}^{y}+a_{j, t+1} & \leq w_{j t} h_{j t}-\tau\left(w_{j t} h_{j t}\right)+b\left(1-h_{j t}\right)+R a_{j t} \\
\text { Away: } & c_{j t}^{y}+g_{j t}^{y}+a_{j, t+1}-\chi-\kappa\left(1-r_{j, t-1}\right) & \leq w_{j t} h_{j t}-\tau\left(w_{j t} h_{j t}\right)+b\left(1-h_{j t}\right)+R a_{j t} \quad+T_{j t}
\end{array}
$$

Parent Budget Constraints Parents have an exogenous constant income stream, $I_{j}^{p}$, which differs across families. ${ }^{28}$ Parental income can be used to purchase private consumption goods,

\footnotetext{
${ }^{25}$ Altruism is the mechanism that is used to generate financial transfers from parents to youths in the model. However when youth and parents have identical homothetic preferences over consumption, altruism places a strong restriction on the relationship between parental income and financial transfers. In particular, transfers are approximately linear in parental income (exactly linear in a static version of the model), which is at odds with the data, if the transfer data are taken at face value. This issue is discussed further and possible alternative formulations that relax this relationship are suggested in Section 5.3.

${ }^{26}$ The monthly wages from the NLSY97 which are used in the estimation of the model are gross of labor income taxes, which necessitates the inclusion of a tax function in the model. The assumed tax function is based on the US tax system in 2007 and is described in Appendix A.

${ }^{27} \mathrm{I}$ assume that youths do not have the ability to borrow so $a_{j, t+1} \geq 0$.

${ }^{28}$ The assumption that parental income is constant could be relaxed without any additional difficulty. It is retained to allow the focus to be placed clearly on the interaction of coresidence and labor market shocks for youths. Studying the interaction between shocks to parents and shocks to youths is an important avenue for future research.
} 
$c_{j t}^{p}$, and public consumption goods, $g_{j t}^{p}{ }^{29}$ In addition, parents can make non-negative financial transfers, $T_{j t}$, to youths. The parental budget constraint is hence given by

$$
c_{j t}^{p}+g_{j t}^{p}+T_{j t} \leq I_{j}^{p}-\tau\left(I_{j}^{p}\right)-\chi
$$

Resource Sharing Across Generations To understand the mechanisms in the model for sharing resources across generations, it is worth taking stock of the various technologies for transferring utility from parents to youths. The model features two forms of parental support: coresidence and financial transfers. For a youth living away from his parents, financial transfers are the only means that parents have to share resources: providing an additional unit of assets to the youth requires the parent to forgo one unit of current period consumption. ${ }^{30}$

Coresidence is also a technology for intergenerational transfers. To use it requires a fixed monthly cost through forgone utility from independence $(z)$. The return from paying this utility cost comprises two parts. First, there is a fixed monthly benefit from the savings in housing costs $(\chi)$. Second, coresidence reduces the cost of transferring additional units of resources from parents to youths, through the presence of the public good. The extent of this 'cost-saving' benefit of coresidence is determined by the weight on public goods in the utility function, $\phi$, which in this setting plays the role of economies of scale. Conditional on living at home, the marginal cost for the parent of providing an additional unit of resources to the youth is increasing in $\phi$ and approaches zero as $\phi$ approaches one (full economies of scale).

Note also that the only component of coresidence that does not enter through consumption is the forgone utility from independence when living at home $(z)$. With decreasing marginal utility, this component dominates as consumption increases, implying that $z$ becomes relatively more important (and hence coresidence less attractive) as the youth's assets increase.

Labor Market Search There are two labor market states: employment and non-employment. Labor market shocks are assumed to be realized at the beginning of each period. I thus describe the structure of the labor market from the vantage point of a youth's labor market status in the previous period. At the beginning of month $t$, a youth who was not working in month $t-1$ receives an offer to work with probability $\lambda_{0}$. Offers are assumed to be drawn from a lognormal distribution

$$
\log w_{j t} \sim N\left(\mu_{0 t}, \sigma_{0}\right)
$$

\footnotetext{
${ }^{29}$ The assumption that parents do not borrow or save is not innocuous. It implies that financial transfers to youths affect parental consumption in the period that they are made and cannot be spread over future periods. This limits the extent to which parents will use financial transfers to offset the effects of labor market shocks to the youths, relative to a case where parents could use their own savings to smooth the impact of financial transfers on their own consumption. However, relaxing this assumption would introduce an additional continuous state variable and significantly complicate computation and estimation of the model.

${ }^{30}$ Because a non-resident youth's savings and/or labor supply decision may adjust in response to a transfer from the parent, the cost to the parent of providing a unit of consumption to a non-resident youth may be different from 1 . The actual cost is given by $\frac{\partial c^{y}}{\partial a}$ where $a$ is the resources of the youth.
} 
where $\mu_{0 t}=\mu_{0}+\mu_{g} t$ so that the mean offer distribution is allowed to drift upwards with age, reflecting general experience effects. A youth who receives an offer may accept it and work in period $t$, or reject it and hope to receive another offer in month $t+1$. At the beginning of month $t$, a youth who worked in month $t-1$ at a wage $w_{j, t-1}$ will find himself in one of three possible situations:

1. With probability $\delta$ the job is exogenously destroyed. A youth who loses his job in this way must spend period $t$ not working $\Rightarrow h_{j t}=0$.

2. With probability $\lambda_{1}$ the youth receives a new wage draw. Conditional on such a wage change, wages are assumed to follow a random walk in logs with drift.

$$
\begin{aligned}
\log w_{j t} & =\mu_{d}+\log w_{j, t-1}+\varepsilon_{j t} \\
\varepsilon_{j t} & \sim N\left(0, \sigma_{1}\right)
\end{aligned}
$$

Note that the youth has the option of rejecting the new wage offer in favor of nonemployment. In this case the youth spends period $t$ not working. However, the youth does not have the option of staying at his current job at his existing wage: these wage shocks are intended to be a reduced-form way of capturing both fluctuations in the quality of worker-firm matches, and new job offers that arise from on-the-job search. $\mu_{d}$ will be estimated to be close to zero but positive, implying that on average, on-the-job wage shocks represent good news, and youths face upward sloping expected earnings profiles (returns to tenure). However, there is some risk attached to a wage change, as new wages may be below existing wages. This feature is necessary to produce the non-negligible numbers of downward earnings movements that are observed in the data, without intervening periods of non-employment. ${ }^{31}$

3. With probability $1-\delta-\lambda_{1}$ there is no change in the youth's current wage offer. The youth can choose to either continue to work at this wage $\left(h_{j t}=1\right)$ or quit to the not working state $\left(h_{j t}=0\right)$.

The labor market described here incorporates two types of risk, productivity and employment. ${ }^{32}$ Note that conditional on remaining employed, all shocks to wages are permanent. The model also incorporates an option value to search, since not all new wage draws while working result in wage increases, and new draws cannot be rejected in favor of the current wages. The equilibrium of the game between youths and parents will thus feature reservation wages that are a function of all the state variables.

\footnotetext{
${ }^{31}$ Nagypal (2005) provides evidence for these type of job transitions. The literature on labor market search has suggested other mechanisms to rationalize this sort of behavior. See for example Postel-Vinay and Robin (2002).

${ }^{32}$ This is in the spirit of much of the search literature, including Low et al. (2007) who attempt to evaluate the relative importance of each type of risk over the life-cycle.
} 
Using data on wages and employment alone, situations 2 and 3 above, when combined with a quit, cannot be empirically distinguished from job destruction. Together with the fact that rejected offers to the non-employed are not observed, this implies that the labor market parameters cannot be estimated outside the model in a first stage and fed into the structural model. Instead they must be estimated along with the other structural parameters inside the model. The parametric assumptions on the distribution of shocks help to achieve identification. ${ }^{33}$

Without loss of generality we can define $w_{j t}=0$ as the state in which a youth does not have an offer to work at time $t$. Defined in this way the history $w_{j}^{t}$ completely defines the labor market outcomes for youth $j .{ }^{34}$

Government Insurance In the NSLY97 sample described in section 2, 17\% of male youths received a government benefit at some point during their time in the sample. With the exception of unemployment benefits which are received by $6 \%$ of the sample, these are all means-tested benefits. ${ }^{35}$ Following Hubbard et al. (1995), I model means-tested benefits as a consumption floor, $\underline{c}$. Hubbard et al. (1995) show that allowing for the effects of means-tested benefits is important in understanding savings behavior of poor households. Unemployment benefits, $b$, are modeled as a constant benefit that is paid automatically to youths in any period that they do not have an offer to work. The tax function, described in Appendix A, is progressive and as such is an additional form of government insurance.

Initial Conditions A complete description of the model also requires specification of initial conditions for assets, residence and labor market variables. Youths are assumed to have $a_{0}=0$ at age 16. This a reasonable assumption given the large fraction of youths with exactly zero assets reported in Section 2. All youths are assumed to be living at home at $t=-1.36$ An exogenous fraction of youths are assumed to have been working at $t=-1$, and their wages are given by the observed distribution of monthly earnings at age 16 .

Terminal Value Functions Because of the monthly frequency of the model, it is not computationally feasible to solve and estimate the model using a horizon $T$ that corresponds to the end of the lifecycle. Moreover, because our interest is in producing a good model of high-frequency behavior around the time of entry to the labor market, it is not clear that this would be a preferred approach even if it were computationally feasible, given the inherent danger of misspecification in any model of behavior. Instead I choose to specify terminal value functions and solve backwards from these. In order to minimize the impact of assumptions

\footnotetext{
${ }^{33}$ Identification of the labor market and other parameters is discussed further in Section 5.2.

${ }^{34}$ However, note that $w_{j t}$ is not a first-order Markov process since the distribution of $w_{j t}$ conditional on $w_{j, t-1}$, depends also on $h_{j, t-1}$, which is an endogenous variable.

${ }^{35}$ Means-tested benefits include Food Stamps (FS), Aid to Families with Dependent Children (AFDC) and Women, Infants, Children (WIC). WIC is the most commonly (received by $8 \%$ of the sample). This is surprising because it is intended only for females. $90 \%$ of these recipients are in a cohabiting relationship, suggesting that respondents report benefits received by all members of the household.

${ }^{36}$ Note that this only places a minimal exogenous structure on $r_{0}$, which is due to the fixed cost of moving out. Since $r_{0}$ is itself a choice variable, youths are free to move out in the first model period.
} 
about functional form, I solve the model for an additional two years ( 24 periods) past the point at which I have data. ${ }^{37}$

The assumption at $t=T$ is that the interaction between parents and youths ceases and no more financial transfers can be made. At this point, all youths still living at home are forced to move out, labor supply becomes inelastic and there is no further uncertainty about future wages. These assumptions are sufficient to obtain closed-form solutions for the value functions, which are then used as the terminal functions. ${ }^{38}$

Feasible Allocations Consider stochastic processes for labor market variables $\left(w_{t}\right)$ and preference shocks $\left(z_{t}\right)$, and an exogenously given interest rate, $R$, and cost of housing, $\chi$. An allocation in this environment, $s$, is a sequence of functions that map histories of labor market outcomes and preference shocks, $\left\{w^{t}, z^{t}\right\}$, initial conditions $\left\{a_{0}, w_{-1}, h_{-1, r_{-1}}\right\}$ and heterogeneity in parental income $\left\{I^{p}\right\}$ into values for $\left\{r_{t}, h_{t}, c_{t}^{p}, c_{t}^{y}, g_{t}^{p}, g_{t}^{y}, T_{t}, a_{t+1}\right\}$. An allocation is feasible if it satisfies the parental budget constraint (5), the youth budget constraint (4) and the nonnegativity constraints for transfers, assets and consumption. Denote the set of feasible allocations by $\mathcal{S}$.

\section{A Non-Cooperative Repeated Game}

Markov Perfect Equilibrium There are a number of reasonable ways in which allocations could be determined in this environment. As a benchmark case, I consider a decentralized approach without commitment, whereby an equilibrium concept and a timing protocol are specified, and parents and youths make strategic decisions to maximize their expected discounted lifetime welfare. In Appendix D, I compare the estimated allocations to those from an alternate environment with full commitment, where attention is restricted to the subset of $\mathcal{S}$ which is Pareto-efficient between youths and parents, taking prices and stochastic processes as given. There I give arguments to support the decentralized approach without commitment as the preferred modeling choice.

The environment described in Section 3 has a natural interpretation as a stochastic repeated game in which action sets in the stage game are conditioned on a pay-off relevant state vector consisting of the current asset position, $a_{t}$, the residence state in the previous period, $r_{t-1}$, and the realized values of the two shocks $\left(w_{t}, z_{t}\right){ }^{39} \mathrm{In}$ each repetition of the stage game, the youth chooses whether to reside at home or away, whether to work and how much to save and purchase

\footnotetext{
${ }^{37}$ All results are unchanged when the model is solved with an additional 10 years (120 months).

${ }^{38}$ An alternative approach would be to specify the terminal value functions as unknown parametric functions of the state variables, and to estimate these functions along with the other structural parameters. For this approach to be feasible, it is necessary to have high quality data on the state variables in the final period. However after age 20 , asset information in recent waves of the NLSY97 is only collected every 5 years, and hence is only available for a subset of the sample at age 23. Moreover, even with this asset information, it is unlikely that identification of the terminal value functions could be achieved without additional assumptions about functional forms.

${ }^{39}$ The previous period's residence outcome, $r_{t-1}$, is included in the state vector as a result of the fixed cost, $\kappa$, of moving out. If there were no fixed cost it would not be a pay-off relevant variable.
} 
of each type of consumption good. The parent chooses monetary transfers to be paid to the youth, and how to split his income between public and private consumption in the household if the youth lives at home. The distribution of $\left(w_{t+1}, z_{t+1}\right)$ is determined by $\left(h_{t}, w_{t}, z_{t}\right)$. The equilibrium concept that I propose is a Markov-Perfect Equilibrium (MPE) in which all actions are conditioned on only pay-off relevant variables, $x_{t}=\left(a_{t}, r_{t-1}, w_{t}, z_{t}\right) .{ }^{40}$ The structure of the game is summarized in Table 3.

Timing of Stage Game In order to guarantee uniqueness of the MPE, I impose a particular extensive form of the stage game which specifies the order in which parents and youths make their decisions. Attention is then restricted to the unique sub-game perfect equilibrium of this sequential stage game. The assumed timing is as follows. First, the current state $x_{t}=$ $\left(a_{t}, r_{t-1}, w_{t}, z_{t}\right)$ is observed. Then the youth chooses whether to live at home or away $\left(r_{t}\right)$. Next, the parent chooses monetary transfers, $T_{t}$, and public consumption $\left(g_{t}^{y}\right)$. Finally, the youth makes his current period labor supply, $h_{t}$, and consumption-savings decision, $\left(c_{t}^{y}, g_{t}^{y}, a_{t+1}\right)$. The sequence of the stage game is illustrated in Figure 4.

The reason for specifying a timing protocol for the stage game is that the simultaneousmove version may contain multiple Nash equilibria. This is most easily demonstrated in the one-shot static version of the game with exogenous labor supply in Appendix B. The intuition for the appearance of multiple equilibria is that due to imperfect altruism $(\eta<1)$ parents have a weaker direct preference for the youth to live away from home than does the youth. This generates values for preferences, $z$, such that the youth prefers an equilibrium in which he lives away and receives the resulting optimal transfer, while the parent prefers an equilibrium in which the youth is induced to stay at home by the (non-credible) threat of low transfers if he were to move out. However with the assumed timing protocol, these latter equilibria are not sub-game perfect and are ruled out.

This particular timing protocol is motivated in part by casual observation of the way that these interactions take place in reality. It seems reasonable that parents cannot force youths to adhere to a particular consumption/savings policy or labor supply decision rule. Rather, they can only influence these choices through their choice of financial transfers. Similarly, a youth cannot be forced to stay in the parental home if he wants to move out, but must accept whatever resulting transfer the parent decides to make. What he does with that transfer is up to him.

In Appendix C I show how the MPE can be described by a set of Bellman equations. For future reference, it is useful to define $Y_{t}\left(x_{t}\right)$ and $P_{t}\left(x_{t}\right)$ as the continuation value functions for youths and parents along the equilibrium path, and $\tilde{P}_{t}\left(x_{t}\right)$ as the corresponding value from direct utility for parents. Hence $P_{t}\left(x_{t}\right)=\tilde{P}_{t}\left(x_{t}\right)+\eta Y_{t}\left(x_{t}\right)$.

\footnotetext{
${ }^{40}$ Due to the finite horizon and the fact that the adopted timing protocol guarantees a unique sub-game perfect equilibrium in the stage game, the unique Markov Perfect Equilibrium is also the unique sub-game perfect equilibrium of the dynamic game. Moreover, I show in Appendix D that at the estimated parameters, the values from the game lie close to the Pareto frontier. Hence considering alternative timing protocols might lead to different equilibria, but not to more efficient ones.
} 
Determinants of Coresidence and Transfers There is no analytic solution to this game, hence the MPE must be computed numerically by backward induction. Nonetheless, a number of features of the determinants of transfers and coresidence can be described qualitatively. There are four features of the model that help to generate an increasing fraction of youths livings away from home: (i) an increasing earnings profile; (ii) an increasing probability of employment through search; (ii) asset accumulation; and (iv) an increasing preference for living away from home. Youths are more likely to live away from home when earnings, assets or the value of independence is higher. However, the probability of living away from home is ambiguous with respect to parental income. On the one hand, higher parental income generates higher parental transfers and hence a lower earnings/assets threshold for the youth to live away. On the other hand, higher parental income means higher consumption in the parental home, making living at home a more attractive option for the youth.

There are two distinct classes of reasons why a youth may move back home: (i) economic factors that include job loss, wage drops, lower than expected earnings growth and asset decumulation; and (ii) preference shocks $(z)$. However the dynamics of coresidence outcomes for these two types of shocks are likely to be different. Because of the ability to run down assets, a labor market shock may lead to a move back in a subsequent period, rather than in the same period in which the shock occurred. However preference shocks, if they lead to a move back home, are likely to do so in the current period, provided the shocks are sufficiently persistent.

Parental transfers are characterized by equating their marginal value and marginal cost along the equilibrium path. When the youth lives away from home, the marginal cost of additional transfer is the reduction in the value of current period consumption for parents. The marginal benefit comprises both the marginal value of assets for youths (scaled by the altruism factor), plus the marginal benefit to parents of higher assets for the youth, that accrues from lower expected transfers in the future:

$$
\begin{aligned}
\tilde{\phi}\left(c_{j t}^{p}+g_{j t}^{p}\right)^{-\gamma} & \leq \eta \frac{\partial Y_{t}^{4}}{\partial a_{t}}+\beta \frac{\partial E_{t}\left[\tilde{P}_{t+1}\right]}{\partial a_{t}} \\
T_{j t} & =0 \text { if inequality is strict. }
\end{aligned}
$$

where $\tilde{\phi}=\frac{\left[(1-\phi)^{1-\phi} \phi^{\phi}\right]}{1-\gamma}, Y_{t}^{4}$ is the youth's value function conditional on the transfer and residence decisions ${ }^{41}$, and $E\left[\tilde{P}_{t+1}\right]$ is the parent's expected next period direct value function, taking into account the optimal savings and labor supply decision of the youth. It is straightforward to see that other things equal, parental transfers are decreasing in youth assets, earnings and employment, and increasing in parental income.

When the youth lives at home, the parent's problem is complicated by the fact that the youth will benefit from any funds spent on the public consumption good. However, if the youth's

\footnotetext{
${ }^{41}$ See Appendix $\mathrm{C}$ for a precise definition of $Y_{t}^{4}$. This is the youths' value function along the equilibrium path, just prior to the labor supply and savings decision.
} 
optimal choice between public and private consumption $\left(c_{t}^{y}, g_{t}^{y}\right)$ is at an interior point, then it is always optimal for the parent to set $T_{t}=0$. To see this, note that the parent could always obtain a higher pay-off by spending marginal funds on public consumption, $g_{t}^{p}$, rather than transfers, $T_{t}$. That way, the parent gets positive utility from additional current consumption while the youth can cut back on his own expenditures on $g_{t}^{y}$ and so is unaffected. In other words, parental spending on public consumption crowds out the youth's spending on current consumption onefor-one. On the other hand, if the youth's optimal choice for public consumption is at the corner $\left(g_{t}^{y}=0\right)$, then it may be optimal for the parent to make positive financial transfers even when the youth lives at home.

\section{$5 \quad$ Parameter Estimation}

\subsection{Estimation Strategy}

For certain parameters structural estimation inside the model is less crucial than others. As such, the estimation approach involves fixing some parameters exogenously and estimating the remaining parameters using a set of moments from the NLSY97. Those parameters that are set exogenously are shown in Table 4, together with their values.

Externally Calibrated Parameters Both parents and youths are assumed to have a risk aversion parameter, $\gamma$ equal to 1.5 . The interest rate, $R$, is set at $1.5 \%$; the monthly unemployment benefit, $b$, is set at $\$ 500 ;{ }^{42}$ and the monthly consumption floor is set at $\$ 100 .^{43}$ The distribution of parental income is consistently estimated from the NLSY97 data in a first stage. It is discretized to a four-point distribution, reflecting average parental income in each quartile.

The degree of economies of scale in the parental home, $\phi$, and the costs of housing, $\chi$, are particularly important parameters since they determine the economic benefits of coresidence. Although there is some data in the NLSY97 on rental costs, it is missing for much of the sample. The mean reported monthly rent for youths living away from home is $\$ 380$, based on 253 observations out of a total of 1,416 . This number is significantly lower than what is suggested by the 2001 American Housing Survey. For renter-occupied units with low annual household income $(\$ 11,700-\$ 17,550)$, the median monthly rent is $\$ 601$. In the model, $\chi$ refers to both direct and indirect costs of housing such as gas and electricity, so I set its value at $\$ 650$. At the

\footnotetext{
${ }^{42}$ Conditional on receiving unemployment benefits, the mean and median monthly benefits are $\$ 780$ and $\$ 650$. However, in the model all youths are eligible for unemployment benefits in all periods that they do not have a job offer. This is substantially more generous than in the US system, which requires that (i) a worker be laid off through no fault of his own; (ii) a worker satisfies an earnings and/or employment requirement over the previous year; and (iii) a worker collects unemployment benefits for no more than 26 weeks. To partially account for these differences, I reduce the mean amount in the data by around one-third to $\$ 500$.

${ }^{43}$ Combining AFDC, Food Stamps and WIC, the median monthly benefit for the NLSY97 sample is $\$ 220$. Because eligibility and take-up are far from universal, I set the consumption floor at half this value. Results are not sensitive to other values in this range.
} 
estimated parameters, none of the allocations are significantly changed when this is varied up or down by $15 \%$.

Unfortunately, there is not enough information in the NLSY97 data to identify the economies of scale in the parental home, $\phi$, based on observed choices. ${ }^{44}$ Since there is no consumption data in the NLSY97 and the CEX only measures expenditures at a household level, I rather calibrate $\phi$ based on information from household equivalent scales. I consider three of the most commonly used-scales: the 'OECD equivalence scale', the 'OECD-modified scale' and the 'square-root scale'. ${ }^{45}$ For each equivalence scale I compute the percentage increase in income needed by a household to keep welfare constant when moving from a household with two adults, to a household with three adults. These three scales give values of $41 \%, 33 \%$ and $22 \%$ respectively. Viewed through the lens of a static version of the model, these imply values for $\phi$ of approximately $0.2,0.3$ and $0.4{ }^{46}$ I set $\phi=0.3$, the midpoint of these values. ${ }^{47}$

Estimated Parameters The approach for estimating the remaining 15 parameters is to use average moments over the age-range from $16.5-22.5$. I choose moments that are sufficient to identify all the parameters and discuss further which moments help to pin down which parameters in Section 5.2. The full set of moments is shown in Table 5. Of these moments, the only one that relates labor market outcomes to coresidence outcomes is the cross-sectional difference in log earnings between youths living at home and away. This allows me to use the effect of labor market outcomes on coresidence dynamics as an informal out-of-sample test of the mechanisms at work in the model.

The estimated parameters are displayed in Tables 6 and include the labor market parameters $\left(\delta, \lambda_{0}, \lambda_{1}, \mu_{0}, \mu_{g}, \sigma_{0}, \mu_{d}, \sigma_{1}\right)$, the preference shock parameters $\left(\alpha_{z}, \beta_{z}, \sigma_{z}^{2}, \rho_{z}\right)$, the altruism factor, $\eta$, the disutility of work, $v$, the discount factor, $\beta$, and the fixed cost of moving out of home, $\kappa$. These parameters are estimated using a simulated minimum distance estimator with a diagonal weighting matrix. ${ }^{48}$ Asymptotic confidence intervals are calculated using a bootstrap estimator for the covariance matrix of sample moments. ${ }^{49}$

\footnotetext{
${ }^{44}$ With panel data on household level expenditures, one could plausibly use changes in consumption expenditure when an additional member joins or leaves a household as a source of identification. See Lise and Seitz (2009) for an example of this approach using two-person husband-wife households. Identifying economies of scale within households is a long standing research topic in applied econometrics, and one which is beyond the scope of this paper.

${ }^{45}$ See Atkinson et al. (1995) for a comprehensive review of equivalence scales.

${ }^{46}$ Appendix F contains a detailed explanation of the mapping from equivalence scales to the weight on public goods in the utility function

${ }^{47}$ In an earlier draft of this paper, I estimated a similar model under the two extreme assumptions of $\phi=1$ and $\phi=0$. The results were qualitatively similar although the quantitative findings were much larger with full economies of scale $(\phi=1)$.

${ }^{48}$ Estimates are not sensitive to alternative choices of weighting matrices, since all moments are matched well in the estimation.

${ }^{49}$ The matrix of partial derivatives of the moment functions at the estimated parameter values is approximated using numerical differentiation. Step widths of $\pm 1.0 e-7$ are used and the reported standard errors are the average of the standard errors resulting from the two sets of numerical derivatives.
} 


\subsection{Where Does Identification Come From?}

Whenever structural parameters are estimated on the basis of simulated moments, a question of identification naturally arises. Although it is not possible to provide an analytical proof that the parameters are identified using a given set of moments, I address the question of identification in three ways. I start by following two approaches that are accepted as reasonable in the existing literature. First, I examine a numerical estimate of the Hessian of the minimumdistance criterion at the estimated parameter values and ensure that it is non-singular. Second, I verify that the estimation strategy can recover good estimates of the structural parameters using data that is simulated from the model. ${ }^{50}$ Finally, I provide an informal argument that each of the parameters has influence on a subset of the chosen moments and give some intuition for why this is the case. This approach should be persuasive, since it delivers an understanding of why the available moments are sufficient to pin down the parameters. The influence of the parameters on the moments is illustrated in Figure 5. Each figure shows how a selected moment is altered when a certain parameter moves away from its estimated value, holding all other parameters fixed at their estimates. ${ }^{51}$ The features of the data that pin down the parameters are as follows:

Disutility of Work $(\boldsymbol{v})$ Conditional on values for the labor market parameters (see below), the disutility of work is identified by the average fraction of youths who are working in a given month.

Labor Market Parameters $\left(\lambda_{0}, \lambda_{1}, \delta, \mu_{0}, \mu_{g}, \sigma_{0}, \mu_{d}, \sigma_{1}\right)$ Since this is a search model, a standard identification challenge arises as a result of the fact that rejected job offers are not observed. Identification comes from a combination of functional form assumptions for the unconditional and conditional wage offer distributions, and the structural relationship between the disutility of labor and the reservation wage. ${ }^{52}$ The two arrival rates, $\left(\lambda_{0}, \lambda_{1}\right)$, are identified from the probability of working conditional on not working in the previous month, the mean duration of unemployment and the probability of earnings changing between two months, conditional on working in both months. The job destruction rate $(\delta)$ is identified from the probability of not working,conditional on working in the previous month. Given the assumption of log-normality, the five parameters of the wage offer distributions $\left(\mu_{0}, \mu_{d}, \mu_{g}, \sigma_{0}, \sigma_{1}\right)$ are identified from the mean and variance of the distribution of earnings conditional on working, the distribution of earnings conditional on having not worked in the previous period, the mean increase in earnings

\footnotetext{
${ }^{50}$ Both of these checks only suggest local identification. To check for other local minima, a thorough search of the parameter space was performed and while other local minima were found, none of these improved on the fit of the estimated parameters.

${ }^{51}$ The plots in Figure 5 only illustrate that each parameter is pinned down, given the estimated values of the other parameters. They are intended merely to provide intuition as to which moments are important for determining which parameters, and not as a proof of local (let alone global) identification.

${ }^{52}$ Note that the distributional assumption on the wage offer distribution is important for identifying the arrival rate of offers, since it determines the mass of wage offers below the reservation wage. This is standard in estimation of structural search models. See Flinn and Heckman (1982).
} 
conditional on an earnings change and the mean increase in entry earnings. The same difficulty as in Flinn and Heckman (1982) applies here: it is the distributional assumptions alone that make it possible to distinguish a model with low arrival rates and a small mass of offers in the bottom of the wage distribution, from one with a high arrival rate and more low wages. Hence the particular method for discretizing the log-normal offer distribution is not innocuous.

Altruism Factor $(\boldsymbol{\eta})$ The altruism factor is identified by the average fraction of youths that receive positive transfers from their parents in a given year. From equation (6) one can see that an increase in the altruism factor leads to an increase in the marginal benefit of transfers, and hence a decrease in the asset threshold at which optimal parental transfers become zero. Figure 5(a) illustrates this effect.

Preference Shocks $\left(\boldsymbol{\alpha}_{z}, \boldsymbol{\beta}_{z}, \boldsymbol{\sigma}_{z}^{2}, \boldsymbol{\rho}_{z}\right)$ The intercept and slope in the mean utility from independence, $\alpha_{z}, \beta_{z}$, are identified from the average fraction of youths living away from home and the growth in this fraction from age 16.5 to age 22.5. At the estimated parameter values, the effect of $\beta_{z}$ dominates. This is shown in Figures $5(\mathrm{~b})$ and $5(\mathrm{c})$. The variance of preference shocks, $\sigma_{z}^{2}$, which determines the amount of heterogeneity in the relative preference for living away is identified from the average difference in earnings between youths living at home and youths living away from home. Recall from Figure 2 that the earnings of youths at home and away is similar. If there were no preference heterogeneity $\left(\sigma_{z}^{2}=0\right)$, then all coresidence movements would be driven by earnings and asset accumulation, and youths living away from home would, on average, have far higher earnings than youths living at home. As $\sigma_{z}^{2}$ increases, the amount of non-labor market heterogeneity increases. This additional heterogeneity reduces the away-home differential in earnings, as illustrated in Figure 5(d). However, the amount that $\sigma_{z}^{2}$ can be increased is limited by the fraction of youths observed to live away from home, as reflected in Figure 5(e). The persistence of preferences, $\rho_{z}$, is identified by the within-person time-series variation in parental coresidence. Two moments are used: the monthly auto-correlation of coresidence outcomes and the fraction of youths who ever move back home at least once by the age of 22.5 (see Figures $5(\mathrm{f})$ and $5(\mathrm{~g})$ ).

Fixed Cost of Moving Out $(\boldsymbol{\kappa})$ The fixed cost of moving has an asymmetric impact on coresidence movements: its impact on movements out of the parental home is greater than on movements back into the parental home. Hence, conditional on the auto-correlation of preference shocks and the arrival rates for job offers, I use the mean duration of spells back home alongside the fraction of youths ever moving back home as the identifying moments (Figure 5(h) and 5(i)). To see why this works, consider an extreme environment in which the fixed cost is zero. With no fixed cost to moving out, the duration back home for a youth who moves back in response to an unemployment shock will be similar to the duration of unemployment. The extent to which spells back home are longer duration than spells out of work, identifies the fixed cost. The amount that the fixed cost can be increased is limited by the fraction of youths actually 
moving back home.

Discount Factor $(\boldsymbol{\beta})$ The discount factor is identified from the mean level of assets at age $20 .{ }^{53}$ The extent to which assets are accumulated during these years, given the amount of risk that youths face and the implicit insurance from parental transfers and coresidence, identifies the degree of impatience.

\subsection{Results of Estimation: What Determines Living Arrangements?}

The estimated parameter values for the baseline model are shown in Table 6 . The fit of the model, as a function of age, is shown in Figures 6 and 7. In this section I discuss the parameter estimates in terms of their implication for the determinants of living arrangements and transfers.

Preference Shocks and Coresidence Patterns The model is able to account for the key coresidence patterns in the data, shown in Figure 6. The growth in preferences, $\beta_{z}$, is best measured in terms of the extent to which it accounts for the increase in the fraction of youths living away home from age 16 to 22 . When $\beta_{z}$ is set to 0 , with all other parameters left at their estimated values, the model generates $34 \%$ of the increase in the fraction of youths living away from home. This implies that around two-thirds of the increase in the fraction living away is due to an increasing preference for independence. The other third is driven by purely economic factors: increasing earnings, employment and the accumulation of assets.

As discussed in Section 5.2, a large amount of heterogeneity in preferences, $\sigma_{z}$, is needed to match the small difference in earnings between youths away and at home. This difference is shown in Figure 6(d). Notice that the model is able to endogenously generate a gently increasing age profile of the away-home earnings difference, albeit not as strong an increase as that observed in the data. The reason is as follows. At young ages, the only individuals who move out are those with a very strong preference for living away from home (high $z$ ). To finance their strong desire to live away from home, these youths lower their reservation wages and accept lower paying jobs than youths who are living at home. This selection effect generates a small away-home earnings difference at the youngest ages. However, as the mean value of independence increases and youths have time to receive more offers and accumulate assets, the mix of youths who are living away from home shifts to comprise those who have received more favorable labor market shocks. The difference thus becomes larger at older ages. The high value for $\sigma_{z}$ ensures that there are always some low-earning youths living away from home, and some high-earnings youths living at home, as is implied by the small overall away-home earnings difference in the data.

Next consider the auto-correlation of preference shocks, $\rho_{z}$. This correlation is estimated to be 0.987 at a monthly frequency, which translates to an annual auto-correlation of 0.85 . Thus, although there is a large amount of cross-sectional variation in the relative preference for living away from home (indicated by the high value of $\sigma_{z}$ ) there is much less within-person time-series

\footnotetext{
${ }^{53}$ Although partial asset information is obtained at other ages, the most comprehensive set of data on youth assets in the NLSY97 is collected in the first interview after the respondent turns 20. See Appendix A for details.
} 
variation in preferences. This implies that although non-labor market heterogeneity plays a large role in explaining cross-sectional differences in coresidence outcomes, the labor market is the key factor in explaining individual movements in and out of the parental home.

To illustrate this point, I decompose coresidence patterns in the benchmark equilibrium. I do this by performing a standard within-groups/between-groups variance decomposition for crosssectional (a) coresidence outcomes; and (b) indicator variables for whether a youth moved in or out of home. These decompositions answer questions of the form: How much of the fact that one youth moved back home in a particular month, while another youth did not, is due to the fact that they received different histories of preference shocks? ${ }^{54}$ I find that only $15 \%$ of cross-sectional differences in coresidence are accounted for by labor market shocks. However, a far greater fraction of movements in and out of home are due to labor market events: $38 \%$ of movements back home and $50 \%$ of movements out of home.

An alternative way to assess the relative importance of the labor market and preference for coresidence, is to compare the benchmark model with an alternate model where preference shocks are shut down, but preference heterogeneity is retained. ${ }^{55}$ This is done by leaving all parameters at their estimated values, except for the transition matrix for preferences, which is replaced with an identity matrix. Hence individuals do not experience changes to their value for $z$ over time. I find that without shocks to preferences the model generates $35 \%$ of the number of youths who ever move back home, suggesting that labor market shocks account for around one third of spells back home by this measure.

Altruism Factor and Transfers The value of the altruism factor that is needed to match the fraction of youths receiving a positive transfer is 0.1 . One area where the model fails to fully account for the data is in predicting the level of transfers, conditional on receiving a transfer. This can be seen in Figure 6(f), which show that median transfers are much larger in the model than in the data. However, for the reasons discussed in Section 2, this is to be expected: the measured transfer amounts in the NLSY97 are are likely to be far lower than the true transfers

\footnotetext{
${ }^{54}$ Consider the cross-sectional variation in residence states, $r_{t}$. This can be decomposed as $\operatorname{Var}\left[r_{t}\right]=$ $\operatorname{Var}\left[E\left(r_{t} \mid z^{t}\right)\right]+E\left[\operatorname{Var}\left(r_{t} \mid z^{t}\right)\right]$ where $z^{t}$ denotes the entire history of preference shocks up to time $t$. The first term is the "between" component: variation in $r_{t}$ that is due to cross-sectional differences in the history of realized preferences for living away from home. The second term is the "within" component: differences in coresidence states that exist even within groups of individuals who have experienced exactly the same history of preferences for independence. The fraction that is not accounted for by preferences, and hence is driven purely by labor market differences, is that due to the "within" component: $\frac{E\left[\operatorname{Var}\left(r_{t} \mid z^{t}\right)\right]}{\operatorname{Var}\left[r_{t}\right]}$. In order to calculate this fraction, it is necessary to calculate $E\left[r_{t} \mid z^{t}\right]$, which is a high-dimensional object. To do this, two approximations are made. First, the history is truncated after $d$ periods. Second, I use a flexible nonparametric estimator for the conditional expectation, $E\left[r_{t} \mid z_{t} . . z_{t-d}\right]$. Note that the decomposition could also have been specified in terms of histories of labor market shocks, $w^{t}$. The reason for preferring the decomposition in terms of preferences is that there is much less history dependence in the effects of $z$ than $w$, for the reasons discussed in the text. The calculation is done with $d=3$, and the results are unchanged if a larger value is used.

${ }^{55}$ The hypothetical questions posed in this paragraph asks what would happen to coresidence patterns if the stochastic structure for preferences were changed, and parents and youths optimally adjusted their behavior. In the previous paragraph the question being asked was with respect to the outcomes that we actually observe what fraction of observed coresidence movements in the benchmark equilibrium are due to the labor market?
} 
as implied by the model. ${ }^{56}$ A plausible interpretation of the difference between transfer amounts in the model and the data is a measure of financial support provided by parents that does not come in the form of direct lump sum transfers across generations.

One reason for the high level of financial transfers in the model is the homotheticity of preferences that derives from altruism. This effect can be seen clearly in the simpler static version of the model in Appendix B. There I show that the combination of altruism and identical preferences for youths and parents imply that transfers increase linearly with parental income whereas in the data, transfer amounts are relatively flat with parental income. To simultaneously match the low levels of transfers, high fraction of youths receiving transfers and flat transfers with parental income, the model would need to be changed in a way that generated non-linear Engel curves for parents' expenditures on youths, such as different curvatures of utility for the two generations. ${ }^{57}$

Estimates of Labor Market Parameters All of they key labor market characteristics are matched well by the model and are shown in Figure 7. The parameters that govern the degree of earnings instability suggest that young males who do not go to college face substantial risk in the labor market. There is a $2.4 \%$ monthly probability that a job is destroyed, which translates to an annual probability of just under $35 \%$. However, this is compensated by fairly high arrival rates of wage offers: around $19 \%$ per month when not working and $36 \%$ when working.

Other Parameter Estimates Expressed annually, the estimated discount factor is fairly low: $0.92 .^{58}$ This reflects the small degree of asset accumulation between ages 16 and 20 that is observed in the data. Both the increase in average log assets, and the distribution of assets at age 20, are well accounted for by the model and are shown in Figures 6(g) and 6(h). The fixed cost of moving out is estimated to be approximately $\$ 660$ which is approximately one month's rent. Figure 6(c) shows that this generates a distribution of duration of spells back home that is very similar to the data. Note that only the mean duration, rather than the whole distribution, was targeted in estimation.

Effect of Labor Market on Coresidence Dynamics The key economic forces in the model are those that relate the labor market to coresidence dynamics. Yet the only moment used in estimation that contains joint information on the labor market and coresidence is the cross-sectional difference in average log earnings between youths living at home and youths

\footnotetext{
${ }^{56}$ The assumption implicit in the estimation strategy is that the data correctly reports which youths receive financial transfers from parents in which years, but under-reports the amount of such transfers.

${ }^{57}$ There are other simple changes to the model that would yield one extra parameter that could be used to match the level of transfers in the data. For example, a simple iceberg cost of transferring resources from the parent to the youth. However, such mechanisms are somewhat artificial and imply that parents are extremely altruistic (to match the high fraction of youths who receive transfers) but that the cost of making transfers is extremely high (to match the low transfer amounts). An alternative modification to the model would be to allow a negative correlation between altruism and parental income.

${ }^{58}$ Note that because of the low estimated discount factor for this group of low-skilled males, the effect of the form of the terminal value assumption on parameter estimates is minimal.
} 
living away from home. This leaves open the possibility of using data on coresidence movements, conditional on labor market status, as an informal over-identification test of the mechanisms at work in the model. Table 7 shows the monthly probability of moving in and out of home by employment status in the data and in the estimated model. The model does well in generating employment effects on the probabilities of moving that are of a similar magnitude to the data.

\section{Putting the Model to Work: Coresidence as Insurance}

In this section I use the estimated model to quantify the importance of parents in general, and coresidence in particular, as a means of insuring shocks in the labor market. First, I define a measure of insurance against shocks and use it to compare the value of the different insurance channels in the model, with respect to the loss of a job. Next, I compare youths' consumption response to shocks when they do and do not have access to their parents as a means of insurance. I use these consumption responses to illustrate the potential for crowding out of private transfers within the family by public programs.

\subsection{Measuring Insurance Against Shocks}

Consider a youth and a parent at the beginning of time $t$, after the realization of the shock $\left(w_{t}, z_{t}\right)$ for that period. Recall that the state variables in the MPE are $x_{t}=\left(a_{t}, r_{t-1}, w_{t}, z_{t}, I\right)$ with a corresponding value function $Y_{t}\left(x_{t}\right)$ for the youth. I measure insurance as the degree to which a youth is indifferent between particular realizations of a shock. ${ }^{59}$ Focusing on job destruction as a shock, define the difference in continuation values due to a job loss as

$$
\Delta_{t}\left(x_{t}\right) \equiv Y_{t}\left(a_{t}, r_{t-1}, w_{t}, z_{t}, I\right)-Y_{t}\left(a_{t}, r_{t-1}, 0, z_{t}, I\right)
$$

A youth is fully insured against a job loss if he is indifferent between losing and not losing his job, i.e. if $\Delta_{t}\left(x_{t}\right)=0$. When a youth is not fully insured, we can define the degree of partial insurance, $\xi_{t}\left(x_{t}\right)$, as the compensating asset variation that is necessary to make him indifferent between losing and not losing the job ${ }^{60}$ :

$$
Y_{t}\left(a_{t}+\xi_{t}, r_{t-1}, 0, z_{t}, I\right)-Y_{t}\left(a_{t}, r_{t-1}, 0, z_{t}, I\right)=\Delta_{t}\left(x_{t}\right)
$$

$\xi_{t}\left(x_{t}\right)$ is the answer to the question of how much additional wealth we would have to give a youth with state vector $x_{t}$ to make him indifferent about becoming jobless.

Now consider a modification to the environment that removes a particular insurance channel. Denote the analogous continuation value difference in the resulting MPE as $\hat{\Delta}_{t}\left(x_{t}\right)$. Once again,

\footnotetext{
${ }^{59}$ This definition of insurance departs from some of the existing literature by defining insurance as equalization of utility, rather than equalization of the marginal utility of consumption. I refer to this alternative definition as consumption insurance and examine the consumption response to shocks in Section 6.3.

${ }^{60} \mathrm{An}$ alternate (and equivalent way) to write this is $Y_{t}\left(a_{t}+\xi_{t}, r_{t-1}, 0, z_{t}, I\right)=Y_{t}\left(a_{t}, r_{t-1}, w_{t}, z_{t}, I\right)$.
} 
define the extent of partial insurance, $\hat{\xi}_{t}\left(x_{t}\right)$, as the compensating asset variation for the job loss, but valued according to the value functions in the benchmark equilibrium:

$$
Y_{t}\left(a_{t}+\hat{\xi}_{t}, r_{t-1}, 0, z_{t}, I\right)-Y_{t}\left(a_{t}, r_{t-1}, 0, z_{t}, I\right)=\hat{\Delta}_{t}\left(x_{t}\right)
$$

The reason for using the value functions from the benchmark equilibrium is that we want to express the value differences in the benchmark and alternative environments using the same units. However, since the marginal value of assets may differ across the two equilibria, if we were to calculate $\hat{\xi}$ as the compensating asset variation implied by $\hat{Y}_{t}$, we would risk concluding that the utility loss from losing a job in one environment is larger than in another, simply because assets are not very valuable in that environment. ${ }^{61}$ The way that $\hat{\xi}$ has been defined, it will always be the case that $\hat{\xi}_{t}\left(x_{t}\right)=\xi_{t}\left(x_{t}\right)$ whenever $\hat{\Delta}_{t}\left(x_{t}\right)=\Delta_{t}\left(x_{t}\right)$. We can then define the value of a particular insurance channel against the loss of a job at $x_{t}$ as the proportionate increase in the cost of a job loss due to removing that channel.

$$
\omega_{t}\left(x_{t}\right)=\hat{\xi}_{t}\left(x_{t}\right) / \xi_{t}\left(x_{t}\right)
$$

There are at least two types of benefits to measuring insurance in this way:

Substitution of Independence for Consumption Measuring insurance in terms of the smoothness of consumption is not appropriate (although I do this below, in order to connect with the existing literature, which has largely focussed on this measure) since youths can adjust the inputs to their own welfare (consumption, labor supply, independence) in response to exogenous shocks. Consider for example a youth who moves back home as a result of a job loss shock. This youth is unambiguously worse off as a result of the shock (since he could always have quit his job), but his consumption may actually increase due to the public consumption in the parental home, and reduction in housing costs. For this youth, the welfare cost of the job loss is not realized through a drop in consumption but rather through a loss of independence. On the other hand, if he were restricted from moving back home, he would retain his utility from independence, but suffer a drop in consumption. $\omega_{t}\left(x_{t}\right)$ takes both components of welfare into account, trading them off in the same way that the youth himself would.

Absence of Level Effects An arguably more standard way of measuring the welfare costs from the removal of insurance channels would be to simply compare the equilibrium value functions in the two environments. However this comparison confounds two differences across the environment - differences in the overall level of welfare; and differences in how welfare is

\footnotetext{
${ }^{61}$ Consider for example the case of removing unemployment insurance. Without unemployment insurance, assets are particularly valuable: so even if the utility loss from losing a job is large, the amount of assets that would be needed to compensate for the job loss may be small. Removing an insurance channel affects (i) the level of continuation values; (ii) the difference in continuation values between having and not having a job; and (iii) the marginal continuation value of additional assets. The measure of insurance defined in this section is designed to measure only the second of these effects.
} 
affected by shocks. The insurance value of the change in the environment is only the latter effect, which is what $\omega_{t}\left(x_{t}\right)$ measures. This distinction is particularly relevant in this model, since the presence of public consumption inside the parental home means that the removal of the option of coresidence reduces the opportunity set for consumption. Even in a world without shocks, a youth would be worse off if he could not live at home, simply because there is less consumption available. The size of this effect is directly linked to the level of public goods in the parental home, determined by $\phi$. However, in this paper I am interested in the second of these two effects: not the value of coresidence per se, but the component of that value that is related to the effects of other shocks (e.g. job loss, wages) on welfare.

\subsection{The Value of Parents as Insurance}

I use the estimated model to calculate the value of different insurance channels for a typical 21 year-old male at different parts of the parental income distribution. I consider a youth with the median preference for living away from home and the median assets $(\$ 5,250)$ and monthly earnings $(\$ 1,900)$ among employed youths with that preference for independence.

Median Welfare Cost of a Job Loss Table 8 contains the results of this calculation. For each parental income group, the first two rows show the welfare cost of losing a job in the benchmark MPE. Expressed in terms of assets, the welfare costs of a job loss are around $\$ 10,000$ and are relatively flat across the parental income distribution. These welfare costs translate to an immediate one-time transfer equivalent to around 6 months of earnings. This is consistent with a mean unemployment duration of 6.2. The next three rows show how much these costs are increased by the removal of insurance channels. Removing the option to move back home, increases the cost of a job loss substantially, but this effect decreases as we move up the parental income distribution. The value of moving back home as insurance, as measured by $\omega$, is a factor of 6.0 for a youth from the bottom quartile of the parental income distribution, and decreases to 1.1 for a youth from the top quartile. The main reason for these differences is that without the option to move back home, wealthier parents compensate by increasing financial transfers when a youth becomes unemployed, while poorer parents cannot afford to do so. So the insurance value of being able to move back home is largest for those with the poorest parents, notwithstanding the fact that the level of public consumption provided in the parental home increases as we move up the parental income distribution.

Accordingly, the value of financial transfers moves in the opposite direction with parental income. Since youths with low parental incomes are less reliant on financial transfers for insurance in the benchmark equilibrium, removing this channel has only a small effect on the welfare cost of a job loss: virtually no effect for those in the bottom quartile. However, for youths from wealthy families, the cost of removing financial transfers is large: a factor of 2.9 for a youth from the top quartile of the parental income distribution. There are two contributing factors to the

high insurance value of financial transfers for these youths. First, restricting transfers has the 
direct effect of reducing their net income available for consumption. Second, restricting transfers forces some youths from wealthy families to move back home upon losing a job, reducing their utility from independence.

Summarizing the main findings, we have seen that for poorer families, coresidence is the most important channel of insurance, while for wealthier families, financial transfers are the more important insurance channel.

Welfare Cost of a Job Loss By Earnings and Assets Figure 8 plots the welfare cost of a job loss, $\xi_{t}\left(x_{t}\right)$, in the benchmark equilibrium and with each insurance channel removed, as a function of the youth's earnings immediately prior to the job loss. The four panels plot this function for each quartile of the parental income distribution, again at the median asset level, and express the welfare costs in terms of the number of months of lost earnings to which they are equivalent. The relative position of the four lines illustrate the fact that the relative importance of the different insurance channels discussed above, is robust across the wage distribution. Figure 9 plots the same welfare costs as a function of assets, at the median earnings level. In all versions of the model, the welfare cost of a job loss is roughly constant across the asset distribution. This is because a job loss entails a lower utility loss at higher asset levels, but assets are less valuable so more has to be given to compensate for the same utility loss. Figure 9 illustrates that these two effects approximately cancel each other out.

\subsection{Consumption Response to Shocks}

An alternative way to measure the value of insurance is to focus exclusively on consumption fluctuations and ignore compensating utility gains from increased leisure (and reinforcing utility drops from the loss of independence). Much of the existing literature on insurance against labor market shocks has followed this approach. In particular, Blundell et al. (2008) use data from the Consumer Expenditure Survey and the Panel Study of Income Dynamics to measure the extent to which household consumption responds to household-level income shocks in the USA. Kaplan and Violante (2009) compare their findings with the predictions from a model where the only mechanism for smoothing consumption is self-insurance through a risk-free security. We find that in such a world, consumption responds substantially more to income shocks than in the US economy, particularly for young households and for households that are borrowing constrained. In this section I provide some indirect evidence that coresidence may constitute one of the additional mechanisms that young workers use to smooth consumption. ${ }^{62}$

Coresidence Improves Consumption Smoothing Table 9 reports the average percent-

\footnotetext{
${ }^{62}$ In this model household formation is endogenous and the focus is on individual-level consumption of the youth, whereas in the CEX data, households are taken to be a fixed unit and consumption is measured at the household level. The results are intended to indicate that when coresidence is an option, consumption responds less to shocks that if it were ignored. It is not possible to calculate corresponding individual-level consumption drops directly from CEX data.
} 
age drop in consumption associated with a job loss. In the benchmark equilibrium this drop is $24 \%$. When youths are restricted from living with their parents the consumption response from a job loss in the resulting equilibrium increases by 8 percentage points (pp). This suggests that coresidence has a significant impact on the ability of youths to smooth consumption, through economies of scale and savings on direct housing costs.

The same is not true for financial transfers. When financial transfers are restricted, the consumption response to a job loss increases by only $2 \mathrm{pp}$. The reason is that removing financial transfers causes many youths to delay moving out of home, or to immediately move back home upon losing their job, since their parents can not provide direct financial support. This means that relative to the benchmark, the utility drop from the loss of a job is realized more through loss of independence, and less through a fall in consumption.

Table 9 also reports how these drops in consumption vary across the parental income distribution. Again, the importance of coresidence for consumption smoothing is most pronounced for youths from the poorest families.

Coresidence Reduces the Consumption Smoothing Benefits of Government Insurance Does the presence of coresidence as a form of within-family transfers limit the value of social insurance programs for young males? To answer this question, I compute the increase in the consumption response to a job loss when the simple unemployment benefits in the model are halved. I then compare this increase, with the increase in the consumption response when the same experiment is done in a world where youths cannot live at home. If the increase is substantially larger in the latter case, it suggests that recognizing the option to live at home can alter our evaluation of the consumption smoothing benefits of unemployment insurance. This is exactly what I find: reducing $b$ by half in the benchmark equilibrium increases the average fall in consumption by 3pp. However without coresidence, this reduction in unemployment benefits increases the consumption response by 9 pp: 3 times as much as when coresidence is ignored. Hence ignoring the endogenous response of coresidence to changes in the level of publicly provided support may lead to overstated assessments of the consumption smoothing benefits that such support provides to youths.

\subsection{Parental Support Distorts Savings Behavior}

In this section I illustrate how the Samaritan's dilemma (see Buchanan (1975) and Bruce and Waldman (1990)) implicit in the model of altruism and financial transfers distorts youths' savings behavior. The effect is reminiscent of the findings in Hubbard et al. (1995), who showed that the asset-based means-testing in the U.S. social insurance system provides a disincentive to accumulate private savings and can thus help explain the low observed savings rates of households with low lifetime earnings. For young people, the implicit conditioning of parental transfers on youths' assets has an analogous effect. Thus the model is able to generate low savings rates for youths without appealing to an unrealistically low discount factor. 
These effects are illustrated in Figure 10 and Table 10 . Figure 10 shows the age profile of average asset holdings in each quartile of the parental income distribution in the benchmark equilibrium, and in the equilibrium with each form of parental support removed. First, note that financial transfers have a very large effect on youths' incentives to save in the top three parental income groups. Table 10 reports that by age 23 average assets are $127 \%$ higher for the top quartile when financial assets are restricted. For the two middle parental income quartiles, assets are $26 \%$ and $63 \%$ higher, while for the lowest parental income group (for whom transfers are very small in the baseline equilibrium), there is no effect. Note that coresidence plays an important role in these counterfactual savings outcomes. When transfers are restricted, coresidence rates increase, particularly at younger ages, providing youths the means to accumulate the precautionary savings that will compensate for the lack of future transfers.

Coresidence itself has two offsetting affects on youth savings. On the one hand, removing this insurance channel generates a stronger precautionary motive for savings. On the other hand, not being able to live at home leads to a large cost in terms of current resources, from both rent obligations and the lack of public goods in the parental home. This makes it more difficult to save. For the higher parental income groups this second effect dominates, and average assets are lower when coresidence is restricted. For the lower parental income groups the first effect is stronger, for two reasons: first, youths from poorer families are more reliant on coresidence as an insurance channel; and second, the amount of public goods that are lost from not being able to live at home is smaller.

\section{Conclusions}

This paper started by documenting several new facts about the dynamics of parental coresidence and labor market outcomes for low-skilled youths in the USA. I showed that the living arrangements of many young adults are characterized by a transitional phase between adolescence and adulthood, in which youths alternate between periods of living with their parents and periods of living independently. These coresidence movements take place against a backdrop of substantial labor market risk, at an age when minimal use is made of traditional insurance mechanisms. By estimating the structural parameters of a dynamic model of the interactions between youths

and their altruistic parents, I showed that the option to move in and out of home is a valuable form of insurance against shocks in the labor market, particularly for youths from low-income households.

In order for the model to simultaneously account for both the cross-sectional and panel dimension of the data, two types of exogenous shocks were needed. The first were a stochastic process for preferences that directly alter youths' relative desire to live away from their parents. The second were labor market shocks, that take the form of the arrival of job offers, job destruction and productivity changes on the job. By exploiting the panel dimension of the data, it was 
possible to disentangle the relative contribution of each type of shock to coresidence outcomes. It turned out that while the cross-section of living arrangements is determined primarily by cross-sectional differences in preferences, labor market shocks are an important determinant of the dynamics of movements in and out of the parental home.

This link between the labor market and coresidence helps to shed light on other important aspects of young workers' behavior. I argued that by reducing the consumption response to labor market shocks, the option to live at home can help explain why young households appear to have access to insurance possibilities over and above that implied by self-insurance through savings. I also showed that through its effect on the incentives to accumulate precautionary savings, parental support can generate a plausible mechanism for explaining the low savings rates of low-skilled youth.

At a policy level, the implications of parental coresidence are also potentially far-reaching. The fact that living arrangements respond endogenously to the realization of labor market shocks, suggests the possibility of substantial crowding out by social insurance programs. Since many public programs are designed to insure against the same types of idiosyncratic labor market shocks that living arrangements respond to, it is important to consider the impact on coresidence when evaluating their welfare implications. Examples of policies that condition on living arrangements include those that require means-testing at a household level (e.g. Food Stamps Program) and those that link benefit entitlements to the structure of households (e.g. Temporary Assistance for Needy Families).

There are a number of important avenues for future research. First, endogenous household formation may also play an important role as insurance for other subgroups. For example, college-educated youths may use coresidence in a similar way once they enter the labor market. Older workers may use the formation and dissolution of marriages and cohabiting relationships as an insurance channel against individual-level shocks. Second, macroeconomics has traditionally studied childhood and adulthood in isolation, as two distinct and separate stages of the lifecycle. This paper suggests that there is an important transitional phase, where interactions between housing, career and marital decisions may have long-term implications. 


\section{References}

Altonji, J., Hayashi, F. and Kotlikoff, L. (1997), 'Parental Altruism and Inter Vivos Transfers: Theory and Evidence', The Journal of Political Economy 105(6), 1121-1166.

Atkinson, A., Rainwater, L. and Smeeding, T. (1995), Income distribution in OECD countries: evidence from the Luxembourg Income Study, Organisation for Economic Co-operation and Development.

Attanasio, O. and Davis, S. (1996), 'Relative Wage Movements and the Distribution of Consumption', The Journal of Political Economy 104(6), 1227-1262.

Becker, G. (1974), 'A Theory of Social Interactions', The Journal of Political Economy 82(6), 1063-1093.

Becker, S., Bentolila, S., Fernandes, A. and Ichino, A. (2008), 'Youth Emancipation and Perceived Job Insecurity of Parents and Children', Journal of Population Economics pp. 1-25.

Bethencourt, C. and Rios-Rull, J. (2007), 'On the Living Arrangements of Elderly Widows', CAERP Discussion Paper.

Bianchi, S., Hotz, V., McGarry, K. and Seltzer, J. (2006), Intergenerational Ties: Alternative Theories, Empirical Findings and Trends, and Remaining Challenges, in 'Caring and Exchange Within and Across Generations', Washington, DC: Urban Institute Press.

Blundell, R., Pistaferri, L. and Preston, I. (2008), 'Consumption inequality and partial insurance', American Economic Review 98(5), 1887-1921.

Bruce, N. and Waldman, M. (1990), 'The rotten-kid theorem meets the Samaritan's dilemma', The Quarterly Journal of Economics 105(1), 155-165.

Buchanan, J. M. (1975), The Samaritan's Dilemma, in E. Phelps, ed., 'Altruism, Morality and Economic Theory', New York: Russell Sage Foundation.

Buck, N. and Scott, J. (1993), 'She's Leaving Home: But Why? An Analysis of Young People Leaving the Parental Home', Journal of Marriage and the Family 55(4), 863-874.

Chatterjee, S., Corbae, D., Nakajima, M. and Ríos-Rull, J. (2007), 'A Quantitative Theory of Unsecured Consumer Credit with Risk of Default', Econometrica 75(6), 1525-1589.

Costa, D. (1999), 'A house of her own: old age assistance and the living arrangements of older nonmarried women', Journal of Public Economics 72(1), 39-59.

Cubeddu, L. and Rios-Rull, J. (2003), 'Families As Shocks', Journal of the European Economic Association 1(2-3), 671-682. 
Danforth, J. (1979), 'On the Role of Consumption and Decreasing Absolute Risk Aversion in the Theory of Job Search', Studies in the Economics of Search pp. 109-31.

DaVanzo, J. and Goldscheider, F. (1990), 'Coming Home Again: Returns to the Parental Home of Young Adults', Population Studies 44(2), 241-255.

Deaton, A. and Paxson, C. (1994), 'Intertemporal Choice and Inequality', The Journal of Political Economy 102(3), 437-467.

Ermisch, J. (1999), 'Prices, Parents, and Young People's Household Formation', Journal of Urban Economics 45(1), 47-71.

Ermisch, J. and Di Salvo, P. (1997), 'The Economic Determinants of Young People's Household Formation', Economica 64(256), 627-644.

Fernandes, A., Becker, S., Bentolila, S. and Ichino, A. (2008), 'Income Insecurity and Youth Emancipation: A Theoretical Approach', The BE Journal of Economic Analysis 8 Policy 8(1), 19.

Fernández-Villaverde, J. and Krueger, D. (2007), 'Consumption over the Life Cycle: Facts from Consumer Expenditure Survey Data', The Review of Economics and Statistics 89(3), 552565.

Flinn, C. and Heckman, J. (1982), 'New methods for analyzing structural models of labor force dynamics', Journal of Econometrics 18(1), 115-168.

Fogli, A. (2004), 'Endogenous Labor Market Rigidities and Family Ties', Mimeo, NYU Stern School of Business.

Goldscheider, F. and Goldscheider, C. (1999), The Changing Transition to Adulthood: Leaving and Returning Home, Sage Publications.

Hayashi, F., Altonji, J. and Kotlikoff, L. (1996), 'Risk-Sharing between and within Families', Econometrica 64(2), 261-294.

Hubbard, R., Skinner, J. and Zeldes, S. (1995), 'Precautionary Saving and Social Insurance', The Journal of Political Economy 103(2), 360-399.

Kaplan, G. (2007), 'Inequality and the Lifecycle', Mimeo, $N Y U$.

Kaplan, G. (2009a), 'Boomerang Kids: Labor Market Dynamics and Moving Back Home', Mimeo, Federal Reserve Bank of Minneapolis .

Kaplan, G. (2009b), 'Moving Back Home: Insurance Against Labor Market Risk', Working Paper, New York Univeristy . 
Kaplan, G. and Violante, G. (2009), 'How Much Consumption Insurance Beyond SelfInsurance?', American Economic Journals: Macroeconomics forthcoming.

Krueger, D. and Perri, F. (2006), 'Does Income Inequality Lead to Consumption Inequality? Evidence and Theory', Review of Economic Studies 73(1), 163-193.

Lentz, R. and Tranaes, T. (2005), 'Job Search and Savings: Wealth Effects and Duration Dependence', Journal of Labor Economics 23(3), 467-489.

Lise, J. (2006), 'On-the-Job Search and Precautionary Savings: Theory and Empirics of Earnings and Wealth Inequality', Mimeo .

Lise, J. and Seitz, S. (2009), 'Consumption Inequality and Intra-Household Allocations', Mimeo, $U C L$.

Low, H. (2005), 'Self-insurance in a life-cycle model of labour supply and savings', Review of Economic Dynamics 8(4), 945-975.

Low, H., Meghir, C. and Pistaferri, L. (2007), 'Wage Risk and Employment Risk Over the Life Cycle', Mimeo .

Manacorda, M. and Moretti, E. (2006), 'Why do Most Italian Youths Live with Their Parents? Intergenerational Transfers and Household Structure', Journal of the European Economic Association 4(4), 800-829.

McElroy, M. (1985), 'The Joint Determination of Household Membership and Market Work: The Case of Young Men', Journal of Labor Economics 3(3), 293-316.

Nagypal, E. (2005), 'On the Extent of Job-to-Job Transitions', Unpublished Manuscript, Northwestern University .

Pezzin, L., Pollak, R. and Schone, B. (2007), 'Efficiency in Family Bargaining: Living Arrangements and Caregiving Decisions of Adult Children and Disabled Elderly Parents', CESifo Economic Studies 53(1), 69.

Postel-Vinay, F. and Robin, J. (2002), 'Equilibrium Wage Dispersion with Worker and Employer Heterogeneity', Econometrica 70(6), 2295-2350.

Rosenzweig, M. and Wolpin, K. (1993), 'Intergenerational Support and the Life-Cycle Incomes of Young Men and Their Parents: Human Capital Investments, Coresidence, and Intergenerational Financial Transfers', Journal of Labor Economics 11(1), 84-112.

Rosenzweig, M. and Wolpin, K. (1994), 'Parental and Public Transfers to Young Women and Their Children', The American Economic Review 84(5), 1195-1212. 
Sakudo, M. (2007), 'Strategic Interactions between Parents and Daughters: Co-residence, Marriage and Intergenerational Transfers in Japan', Mimeo .

Storesletten, K., Telmer, C. and Yaron, A. (2004), 'Consumption and risk sharing over the life cycle', Journal of Monetary Economics 51(3), 609-633.

Topel, R. and Ward, M. (1992), 'Job Mobility and the Careers of Young Men', The Quarterly Journal of Economics 107(2), 439-479.

Zhange, H., C. A. and Scheinberg, K. (2009), 'A Derivative-free Algorithm for the Least-square Minimization', Technical Report, CCT-TR-2009-8 . 


\begin{tabular}{l|cc}
\hline \hline & \multicolumn{2}{|c}{ Number of Males } \\
& Lost & Remaining \\
\hline & & \\
Raw NLSY97 & 316 & 4599 \\
Drop resp with 1998 interview missing & 740 & 3543 \\
Drop resp still in high school & 1683 & 1860 \\
Drop resp observed in post-secondary education & 21 & 1839 \\
Drop resp with gaps in coresidence data & 21 & 1818 \\
Drop resp who ever have all parents dead & 131 & 1687 \\
Drop resp ever in military & 1 & 1686 \\
Drop months at age < 16 & 73 & 1613 \\
Drop resp with gaps in employment data & & \\
& & 41406 \\
\hline Final sample & & 25.7 \\
Month/person observations & & 22 \\
Mean observations per person & \multicolumn{2}{|c}{} \\
Median observations per person
\end{tabular}

Table 1: Number of respondents lost at each stage of sample selection

\begin{tabular}{|c|c|c|c|}
\hline \multicolumn{2}{|c|}{ Individual-level Fixed Variables } & \multicolumn{2}{|l|}{ Monthly Variables } \\
\hline \multicolumn{2}{|c|}{ Number Observations } & \multicolumn{2}{|l|}{ Number Observations } \\
\hline White & 0.68 & Age & 19.46 \\
\hline Black & 0.21 & Away & 0.35 \\
\hline Hispanic & 0.15 & Married & 0.03 \\
\hline Age First Observed & 18.18 & Cohabiting & 0.15 \\
\hline Age Last Observed & 20.27 & Working & 0.71 \\
\hline \multirow{9}{*}{$\begin{array}{l}\text { Highest Grade Completed } \\
\text { High School Graduate } \\
\text { Ever Away During Sample } \\
\text { Ever Home During Sample } \\
\text { Move Out During Sample } \\
\text { Move Back During Sample } \\
\text { Ever In Jail } \\
\text { Months in Sample }\end{array}$} & \multirow{3}{*}{$\begin{array}{c}11.47 \\
0.68 \\
0.53\end{array}$} & Monthly Earnings & 2196 \\
\hline & & \multicolumn{2}{|l|}{ Annual Variables } \\
\hline & & \multicolumn{2}{|l|}{ Number Observations } \\
\hline & 0.89 & Has Child & 0.17 \\
\hline & 0.38 & Number of Children & 1.25 \\
\hline & 0.23 & Receive Transfer & 0.32 \\
\hline & 0.06 & Annual Transfer Amount & 974 \\
\hline & 26.06 & \multicolumn{2}{|c|}{ Characteristics of Parents } \\
\hline & & $\begin{array}{l}\text { Number Observations } \\
\text { Number of Parents } \\
\text { Average Age } \\
\text { Biological Parents Married } \\
\text { Total Parents Income }\end{array}$ & $\begin{array}{c}2.25 \\
45.28 \\
0.46 \\
56387\end{array}$ \\
\hline
\end{tabular}

Table 2: Sample summary statistics

\begin{tabular}{l|l}
\hline \hline Predetermined States & $a_{t}, r_{t-1}, h_{t-1}$ \\
Stochastic States & $w_{t}, z_{t}$ \\
Youth Actions & $r_{t}, h_{t}, c_{t}^{y}, g_{t}^{y}, a_{t+1}$ \\
Parent Actions & $c_{t}^{p}, g_{t}^{p}, T_{t}$ \\
\hline \hline
\end{tabular}

Table 3: States and actions for the non-cooperative game 


\begin{tabular}{clc}
\hline \hline Parameter & Description & Benchmark \\
\hline$R$ & Annual interest rate & $1.5 \%$ \\
$\gamma$ & Coefficient of relative risk aversion & 1.5 \\
$b$ & Unemployment benefit & $\$ 500$ \\
$c$ & Consumption floor & $\$ 100$ \\
$\chi$ & Monthly housing cost & $\$ 650$ \\
$\phi$ & Weight on public goods in utility function & 0.3 \\
\hline \hline
\end{tabular}

Table 4: Parameters fixed outside the model

\begin{tabular}{l|l|l}
\hline \hline Labor Market Moments & Coresidence Moments & Other Moments \\
\hline mean, variance log earns & fraction away from home & frac receiving transfers \\
mean, variance log entry earns & mean growth rate in fraction away & age 20 mean assets \\
av growth mean log earns & mean duration spells back home & \\
av growth mean log entry earns & fraction ever moved back & \\
prob start work & auto-correlation coresidence & \\
prob stop work & diff: mean log earns, home vs away & \\
prob earnings change & growth in diff: mean log earns, home vs away & \\
mean log earns change & & \\
fraction not working & & \\
mean unemployment duration & & \\
\hline \hline
\end{tabular}

Table 5: Moments used in estimation 


\begin{tabular}{|c|c|c|}
\hline Parameter & Description & \\
\hline \multicolumn{3}{|c|}{ Labor Market Parameters } \\
\hline$\delta$ & Job destruction probability & $\begin{array}{c}0.024 \\
(0.008)\end{array}$ \\
\hline$\lambda_{0}$ & Job offer probability (not working) & $\begin{array}{l}0.191 \\
(0.017)\end{array}$ \\
\hline$\lambda_{1}$ & New job offer probability & $\begin{array}{c}0.364 \\
(0.011)\end{array}$ \\
\hline$\mu_{0}$ & Mean log wage offer distribution & $\begin{array}{l}6.505 \\
(2.151)\end{array}$ \\
\hline$\mu_{g}$ & Growth rate of mean log wage offer distribution $\left(\times 10^{-2}\right)$ & $\begin{array}{c}0.822 \\
(0.085)\end{array}$ \\
\hline$\sigma_{0}$ & St. dev. log wage offer distribution & $\begin{array}{c}0.540 \\
(0.023)\end{array}$ \\
\hline$\mu_{d}$ & Mean change log wages | wage change $\left(\times 10^{-2}\right)$ & $\begin{array}{l}0.758 \\
(0.130)\end{array}$ \\
\hline$\sigma_{1}$ & St. dev. change log wages $\mid$ wage change & $\begin{array}{c}0.352 \\
(0.008)\end{array}$ \\
\hline \multicolumn{3}{|c|}{ Preference Shocks } \\
\hline$\alpha_{z}$ & Intercept for mean value of living away & $\begin{array}{l}1.065 \\
(0.271)\end{array}$ \\
\hline$\beta_{z}$ & Age slope for mean value of living away & $\begin{array}{c}0.602 \\
(0.166)\end{array}$ \\
\hline$\sigma_{z}^{2}$ & Variance of $(\log )$ value of living away & $\begin{array}{l}13.890 \\
(1.441)\end{array}$ \\
\hline$\rho_{z}$ & Autocorrelation of $(\log )$ value of living away & $\begin{array}{c}0.987 \\
(0.006) \\
\end{array}$ \\
\hline \multicolumn{3}{|c|}{ Other Parameters } \\
\hline$\eta$ & Altruism factor & $\begin{array}{c}0.096 \\
(0.041)\end{array}$ \\
\hline$\nu$ & Disutility of work $\left(\times 10^{4}\right)$ & $\begin{array}{c}0.963 \\
(0.353)\end{array}$ \\
\hline$\beta$ & Monthly discount factor & $\begin{array}{c}0.993 \\
(1.227)\end{array}$ \\
\hline$\kappa$ & Fixed costs of moving out of home $\left(\times 10^{-3}\right)$ & $\begin{array}{c}0.664 \\
(0.150) \\
\end{array}$ \\
\hline
\end{tabular}

Table 6: Parameter estimates, standard errors in parentheses

\begin{tabular}{l|cc|cc}
\hline \hline & \multicolumn{2}{|c|}{ Prob Move Back Home (\%) } & \multicolumn{2}{|c}{ Prob Move Out of Home (\%) } \\
& Data & Model & Data & Model \\
\hline Overall & 3.1 & 2.4 & 2.9 & 2.1 \\
Working & 2.8 & 2.1 & 3.0 & 2.2 \\
Not Working & 3.7 & 3.4 & 2.6 & 1.8 \\
\hline Difference & -0.9 & -1.3 & 0.4 & 0.4 \\
\hline \hline
\end{tabular}

Table 7: Monthly probability of moving in and out of home, by labor market status 


\begin{tabular}{|c|c|c|c|c|}
\hline & \multicolumn{4}{|c|}{ Quartile of Parental Income Distribution } \\
\hline & Q1 & Q2 & Q3 & Q4 \\
\hline $\begin{array}{l}\text { Cost of Job Loss, } \xi_{t} \\
\text {-Compensating asset transfer }\end{array}$ & $\$ 11,100$ & $\$ 11,200$ & $\$ 11,900$ & $\$ 12,100$ \\
\hline -Number of months of earnings & 5.9 & 6.1 & 6.3 & 6.4 \\
\hline $\begin{array}{l}\text { Value of insurance channels, } \omega_{t}^{I} \\
\text { - option to move back home }\end{array}$ & 6.0 & 3.2 & 1.5 & 1.1 \\
\hline - financial transfers & 1.0 & 1.4 & 1.9 & 2.9 \\
\hline - unemployment insurance & 1.7 & 2.0 & 1.4 & 1.4 \\
\hline
\end{tabular}

Table 8: Cost of job loss and value of insurance for 21 year-old with median assets, earnings and preference for independence. Value of insurance $\left(\omega_{t}^{I}\right)$ expressed as multiple of cost of job loss $\left(\xi_{t}\right)$.

\begin{tabular}{l|c|cccc}
\hline \hline & Overall & \multicolumn{5}{|c}{ Quartile of Parental Income Distribution } \\
& & Q1 & Q2 & Q3 & Q4 \\
\hline Baseline UI (\$500 per month) & & & & & \\
Benchmark & 24 & 32 & 27 & 20 & 18 \\
No coresidence & 32 & 50 & 38 & 22 & 22 \\
No transfers & 26 & 32 & 27 & 23 & 21 \\
\hline Reduced UI (\$250 per month) & & & & & \\
Benchmark & 27 & 33 & 29 & 27 & 18 \\
No coresidence & 41 & 47 & 57 & 43 & 18 \\
No transfers & 26 & 33 & 27 & 21 & 21 \\
\hline \hline
\end{tabular}

Table 9: Average percentage drop in consumption in response to loss of a job

\begin{tabular}{l|c|cccc}
\hline \hline & Overall & \multicolumn{4}{|c}{ Quartile of Parental Income Distribution } \\
& & $\mathrm{Q} 1$ & $\mathrm{Q} 2$ & $\mathrm{Q} 3$ & $\mathrm{Q} 4$ \\
\hline Average assets at age 23 & $\$ 6,500$ & $\$ 8,300$ & $\$ 7,400$ & $\$ 5,900$ & $\$ 4,20$ \\
\hline Change from baseline & $(\%)$ & & & $(\%)$ & \\
No move back & -8 & 9.8 & -2.9 & -21 & -36 \\
No transfers & 42 & 0.2 & 25.9 & 62.7 & 126.8 \\
No coresidence & 4.1 & 9.1 & 4.9 & -0.6 & -0.5 \\
\hline \hline
\end{tabular}

Table 10: Average at asset holdings at age 23, expressed as percentage of age 23 average asset holdings in baseline model. 


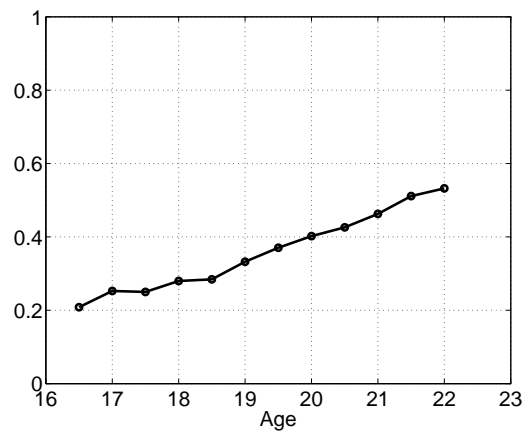

(a) Fraction living away from home

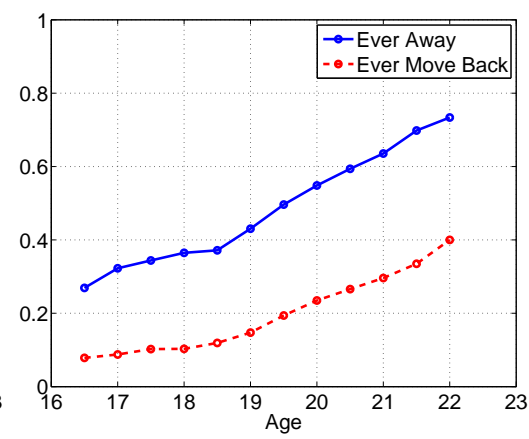

(b) Fraction ever moved back home

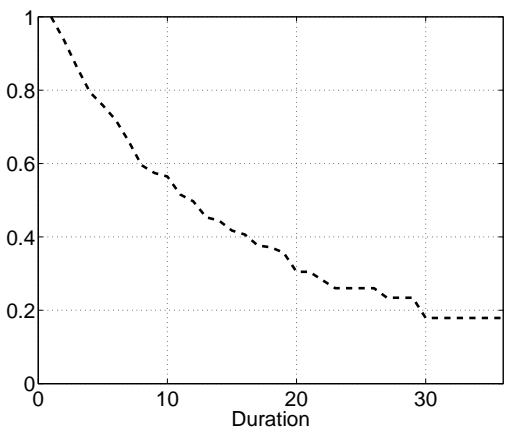

(c) Survival function for spells back home

Figure 1: Coresidence statistics from NLSY97

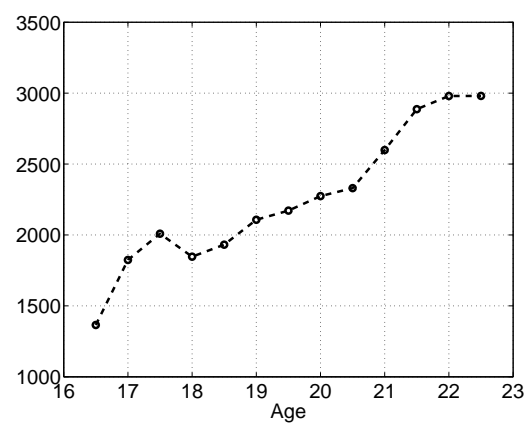

(a) Monthly real earnings

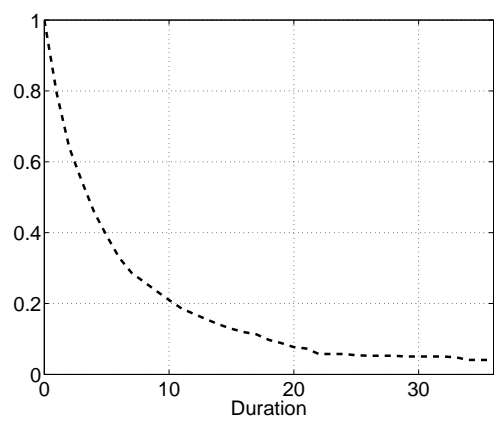

(d) Out of work survival function

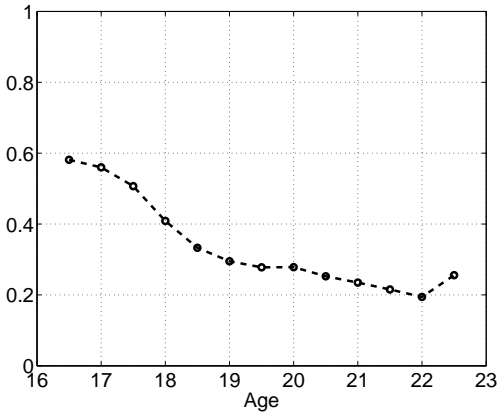

(b) Fraction not working

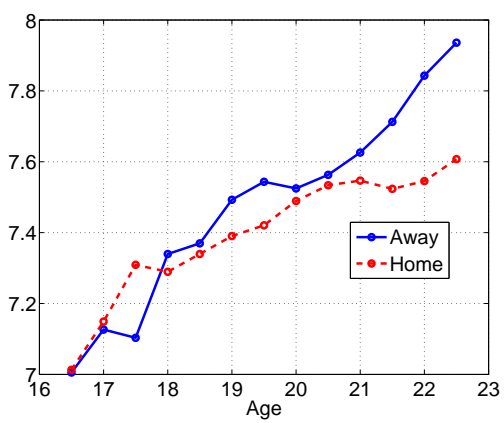

(e) Log monthly earnings by coresidence

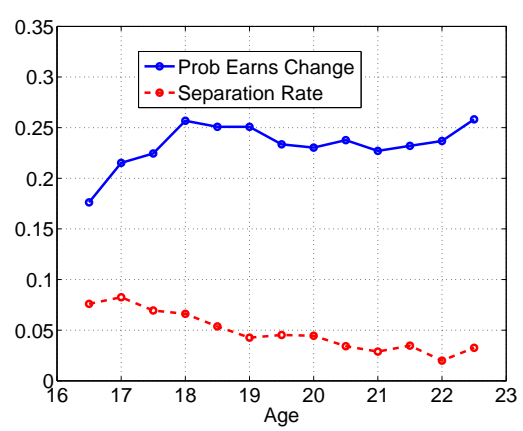

(c) Labor market stability

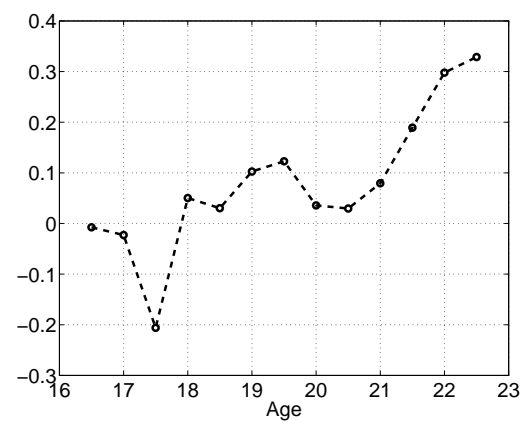

(f) Away-home differences in monthly log earnings

Figure 2: Labor market statistics from NLSY97 


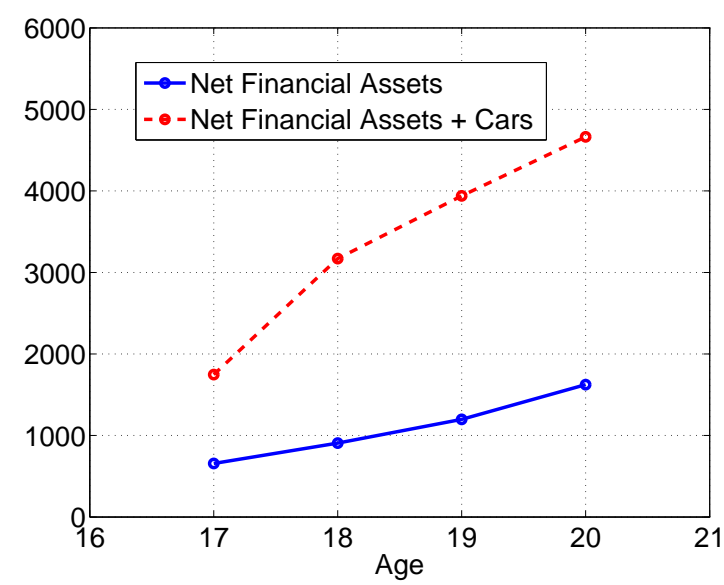

(a) Mean assets

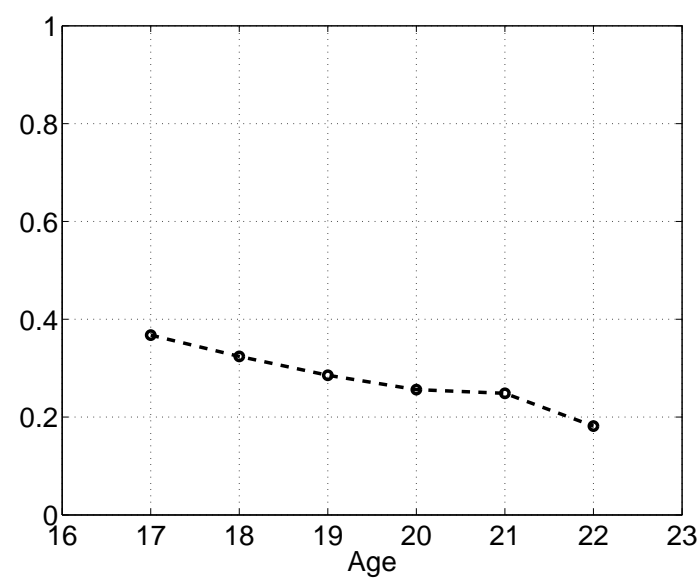

(c) Fraction receiving parental transfers

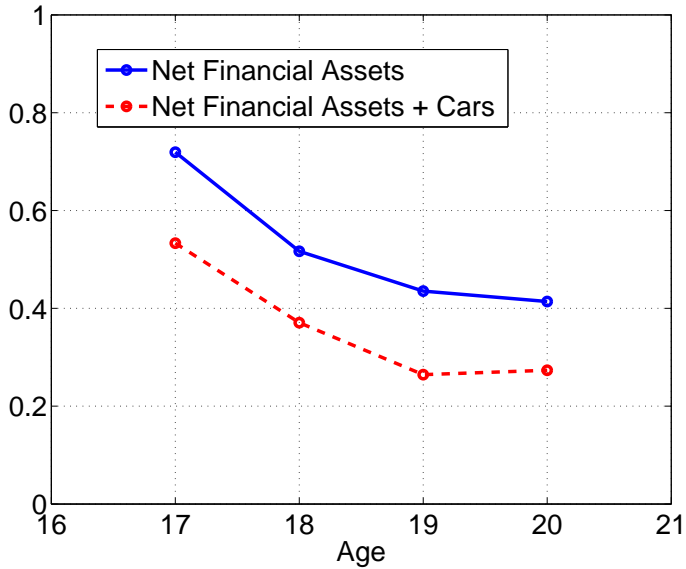

(b) Fraction with zero assets

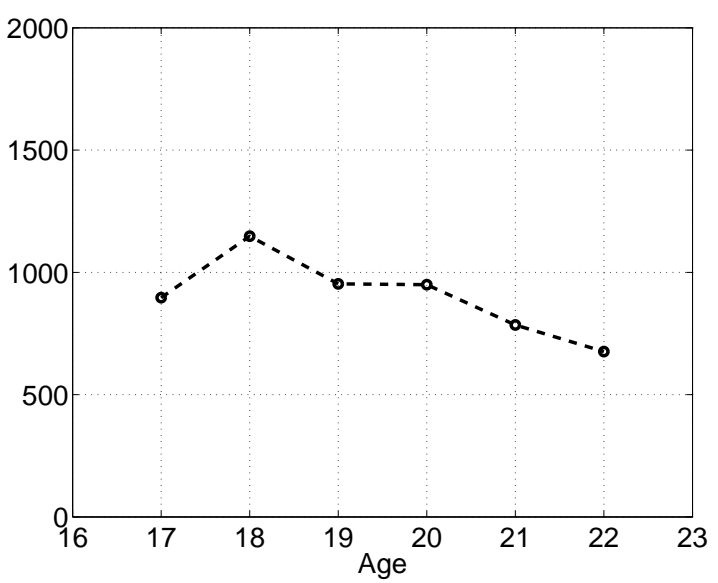

(d) Mean annual parental transfers

Figure 3: Asset and parental transfer statistics from NLSY97

\begin{tabular}{l|c|c|c|c} 
state & nature & youth & parent & youth \\
\hline$a_{t}, r_{t-1}$ & $w_{t}, z_{t}$ & $r_{t}$ & $T_{t}$ & $h_{t}, a_{t+1}$
\end{tabular}

$w_{t-1}, h_{t-1}, z_{t-1}$

Figure 4: Sequence of the stage game 


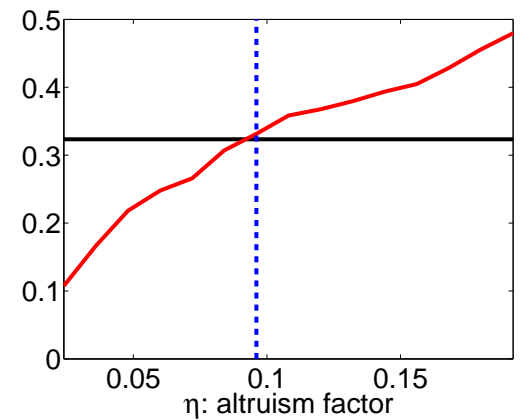

(a) $\eta$ : Fraction receiving transfers

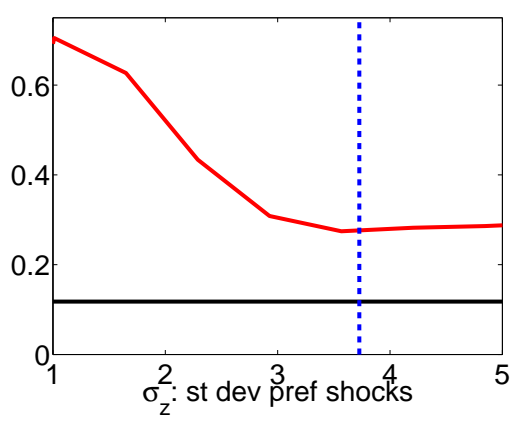

(d) $\sigma_{z}$ : Away-home log earns diff

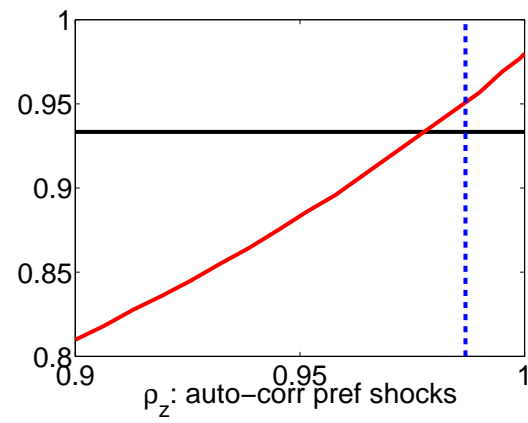

(g) $\rho_{z}$ : Autocorrelation $r_{t}$

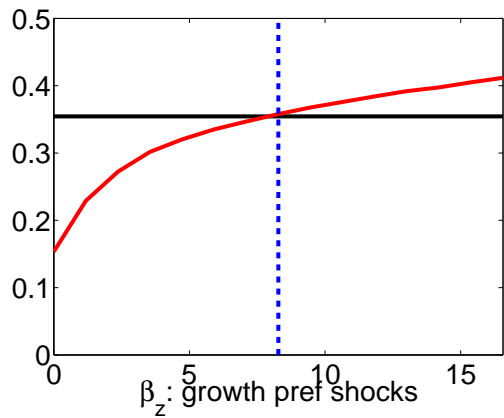

(b) $\beta_{z}$ : Fraction away from home

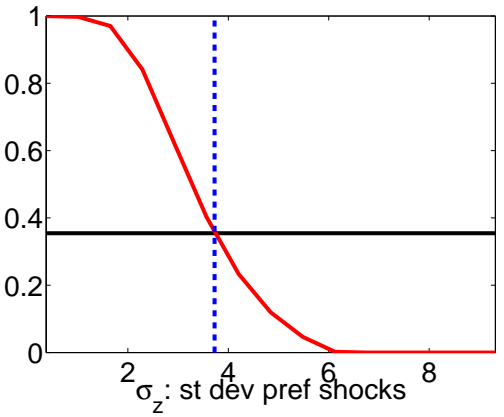

(e) $\sigma_{z}$ : Fraction away from home

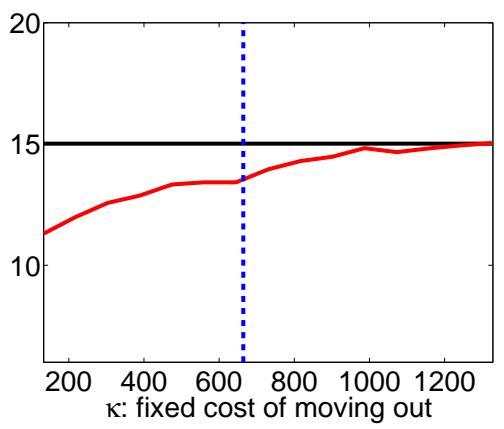

(h) $\kappa$ : Mean back home duration

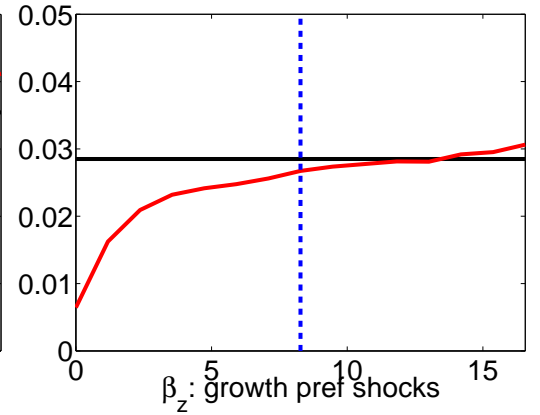

(c) $\beta_{z}$ : Growth frac away

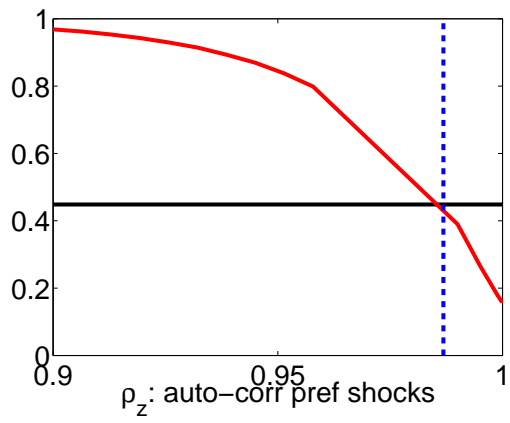

(f) $\rho_{z}$ : Fraction moved back

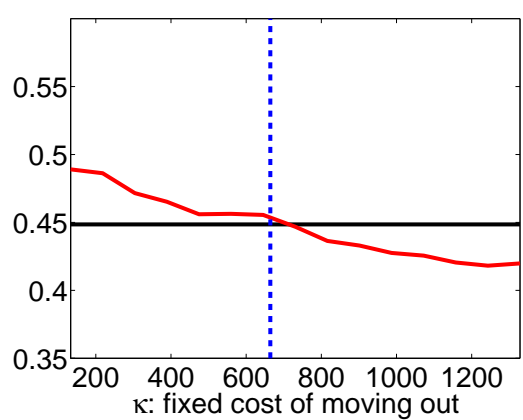

(i) $\kappa$ : Fraction moved back

Figure 5: Relationship between selected moments and parameters, at parameter estimates Notes: Blue dashed line shows point estimate, black solid line shows data. Red line line shows how a particular moment in the model deviates from the corresponding moment in the data as the parameter is moved away from the point estimate. 


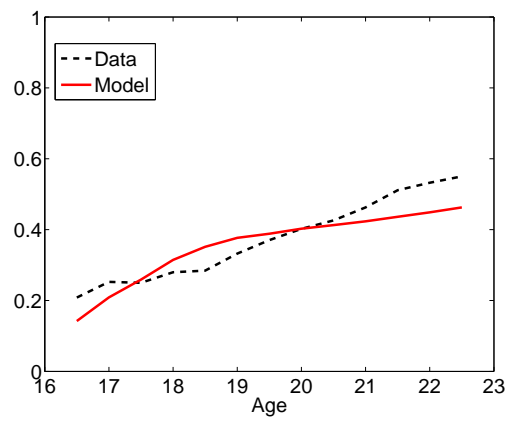

(a) Fraction away from home

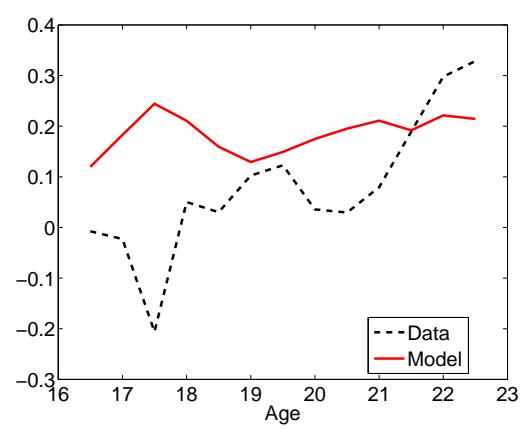

(d) Away-home log earnings diff

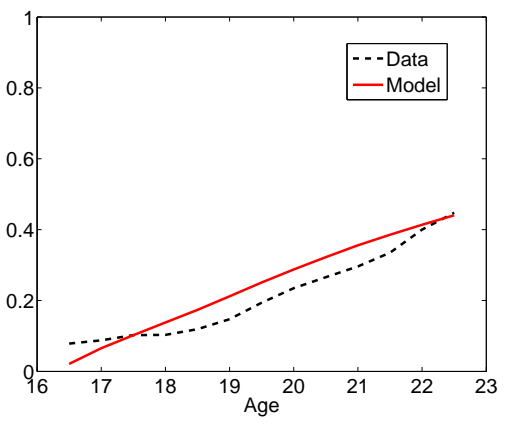

(b) Fraction ever moved back

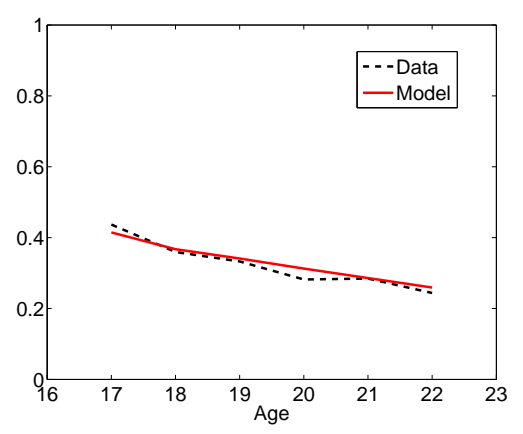

(e) Fraction receiving transfers

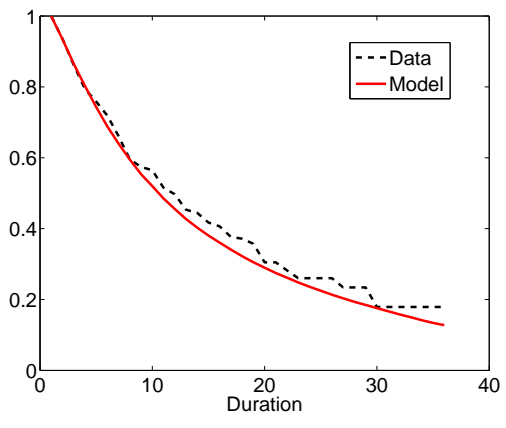

(c) Durations back home

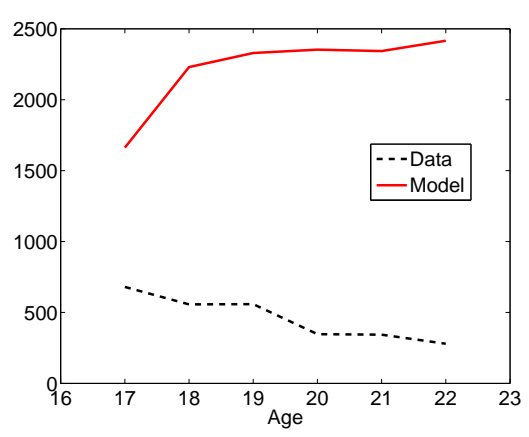

(f) Median transfers

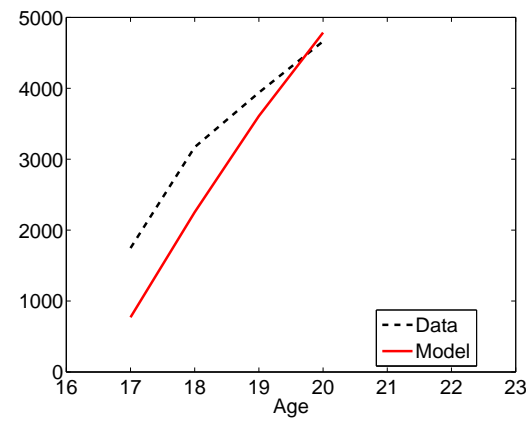

(g) Mean assets

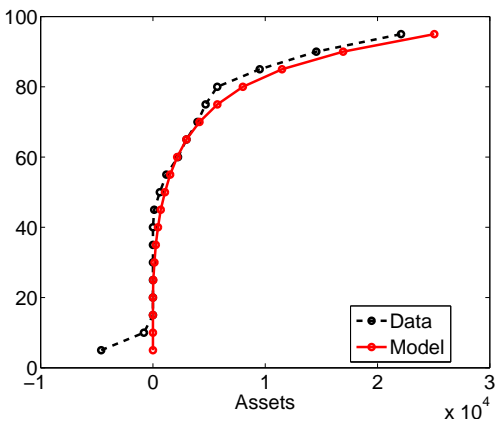

(h) Asset distribution age 20

Figure 6: Model fit, coresidence, transfers and assets 


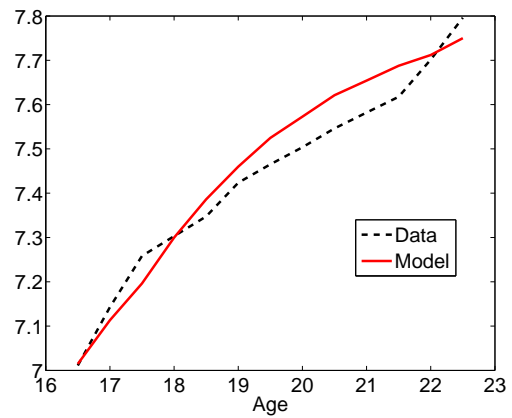

(a) Average log earnings

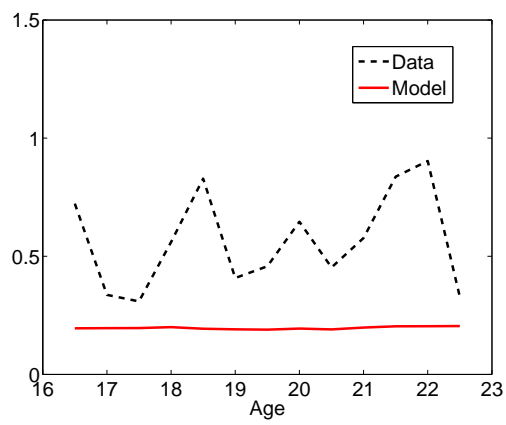

(d) Variance log entry earnings

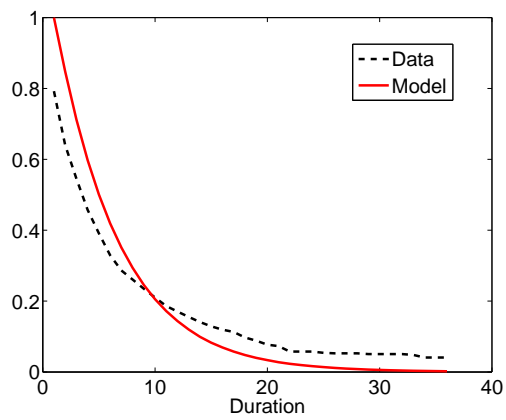

(g) Unemployment durations

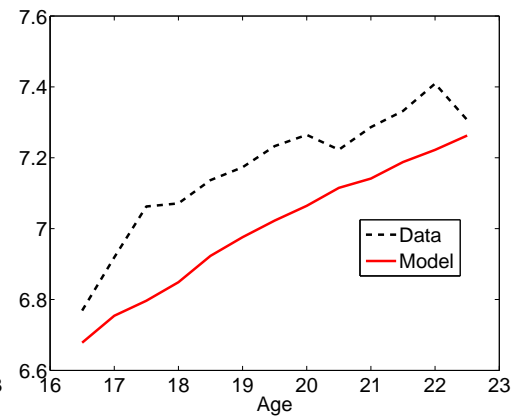

(b) Average log entry earnings

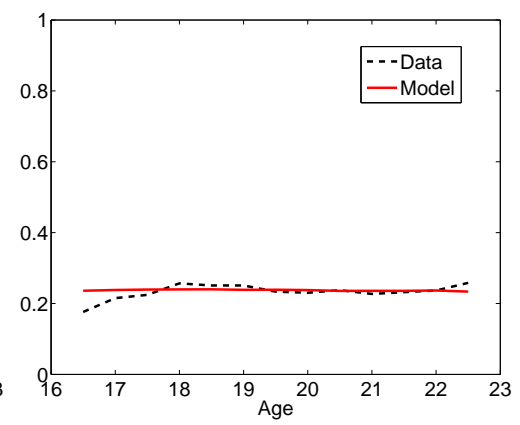

(e) Prob earnings change

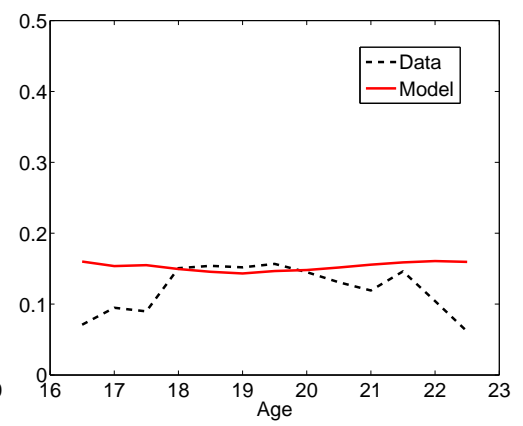

(h) Prob start working

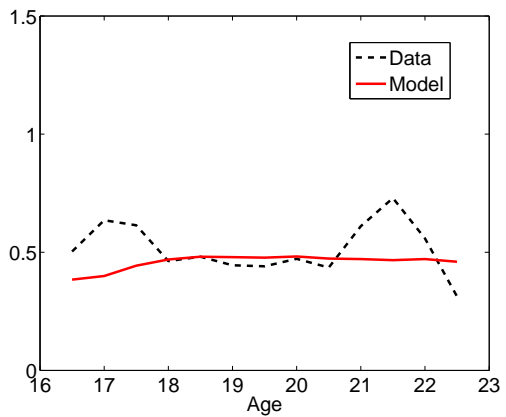

(c) Variance log earnings

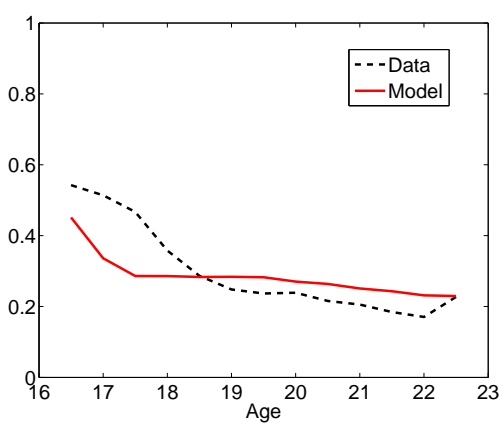

(f) Fraction not working

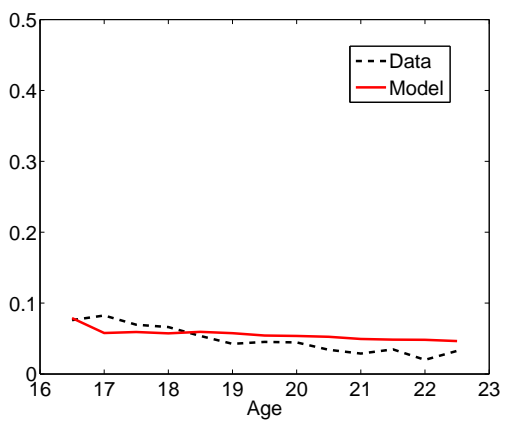

(i) Prob stop working

Figure 7: Model fit, earnings distribution and dynamics 


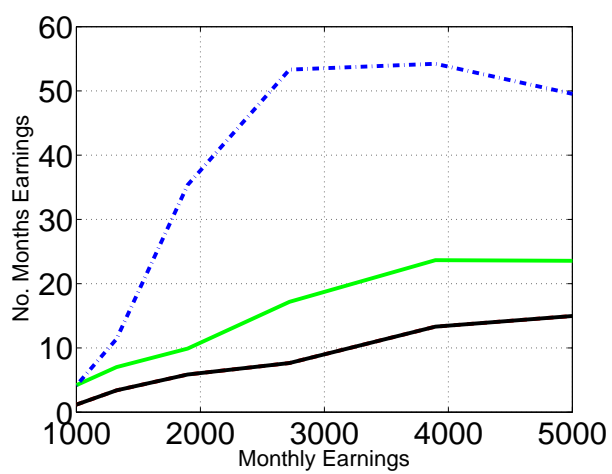

(a) Bottom Quartile Parental Inc Dist

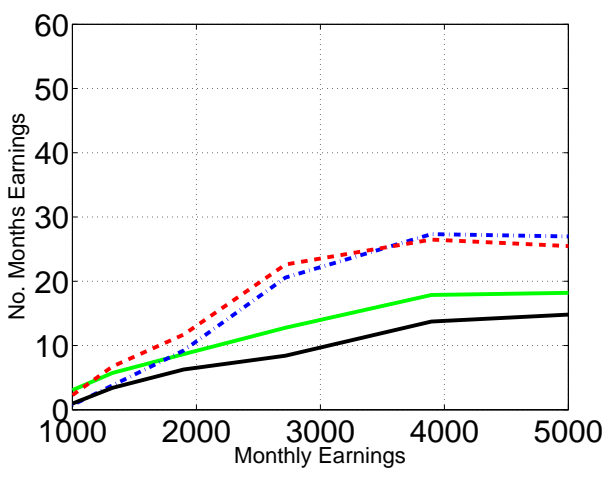

(c) 3rd Quartile Parental Inc Dist

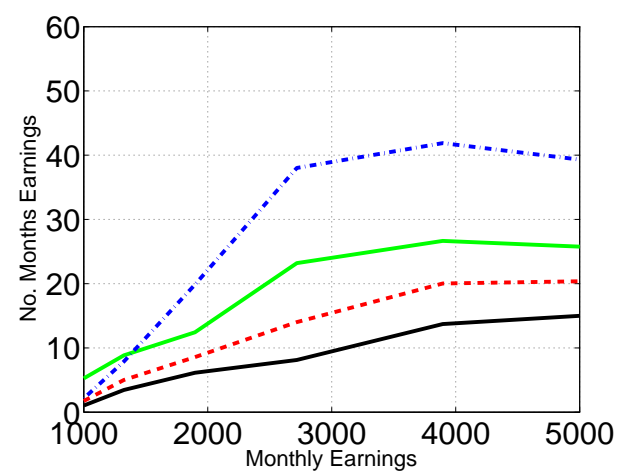

(b) 2nd Quartile Parental Inc Dist

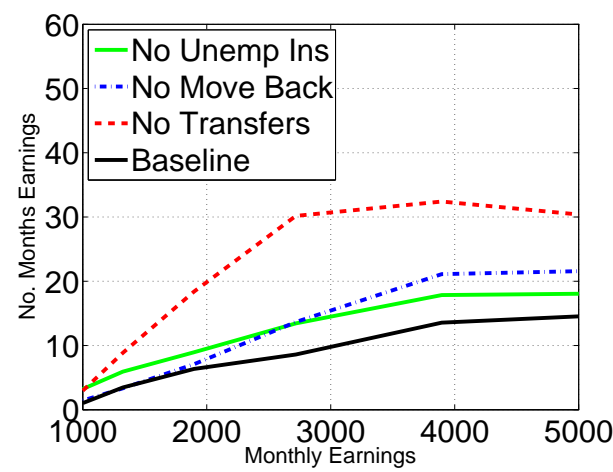

(d) Top Quartile Parental Inc Dist

Figure 8: Welfare cost of a job loss in terms of compensating asset variation expressed as multiples of monthly earnings, by monthly earnings. 


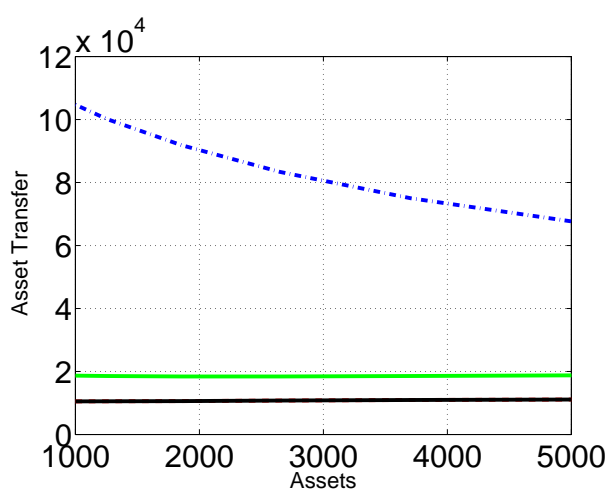

(a) Bottom Quartile Parental Inc Dist

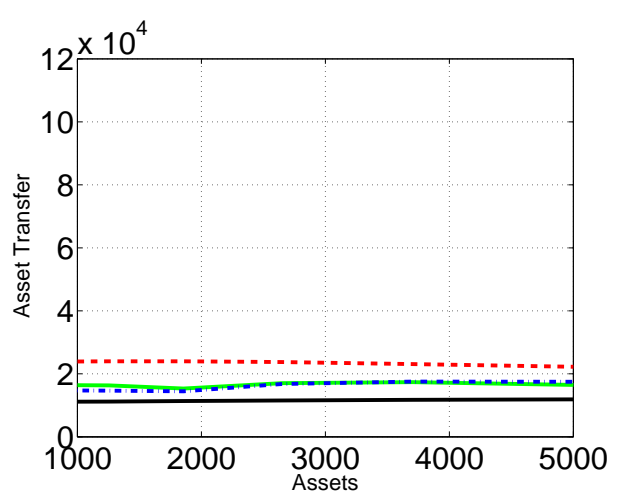

(c) 3rd Quartile Parental Inc Dist

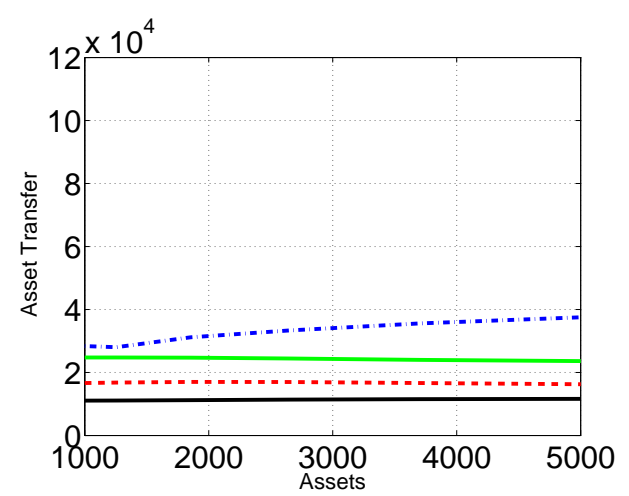

(b) 2nd Quartile Parental Inc Dist

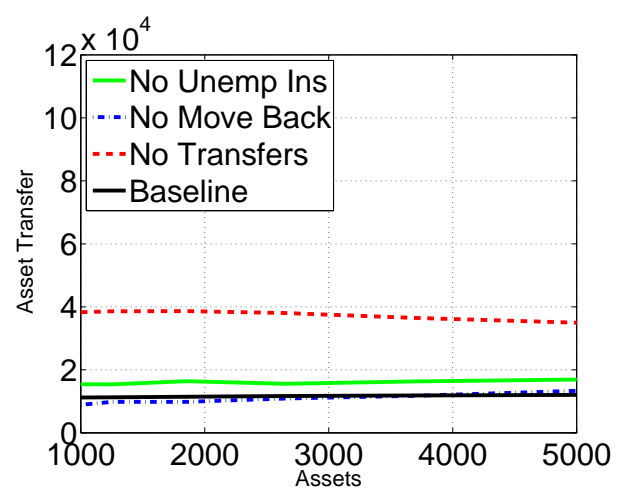

(d) Top Quartile Parental Inc Dist

Figure 9: Welfare cost of a job loss in terms of compensating asset variation, by assets. 


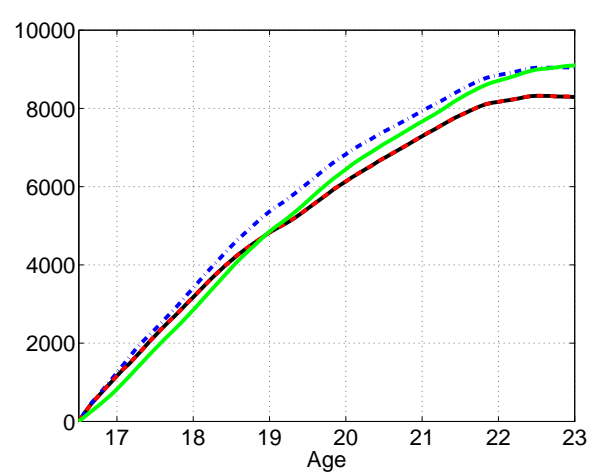

(a) Bottom Quartile Parental Inc Dist

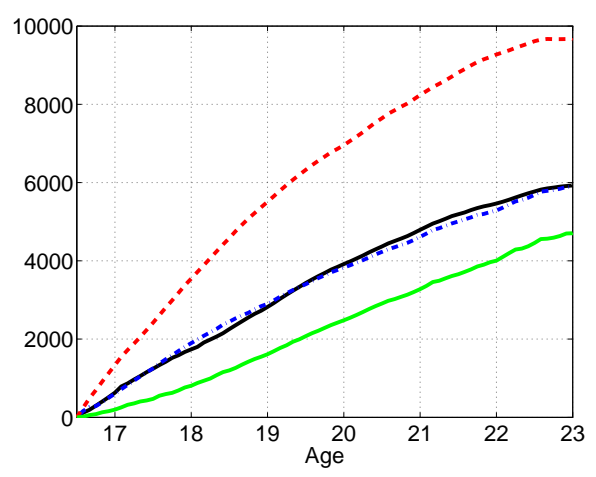

(c) 3rd Quartile Parental Inc Dist

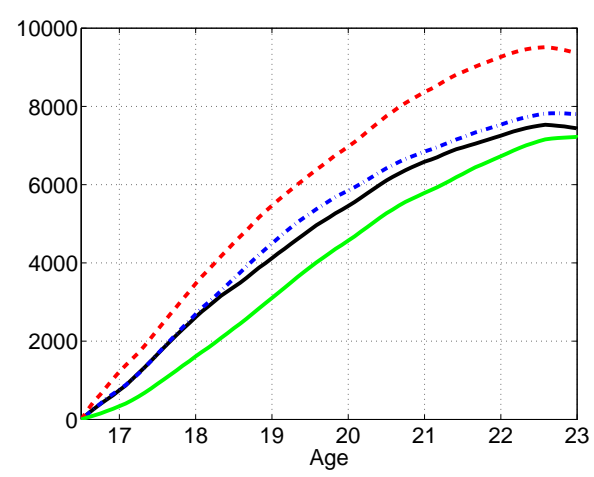

(b) 2nd Quartile Parental Inc Dist

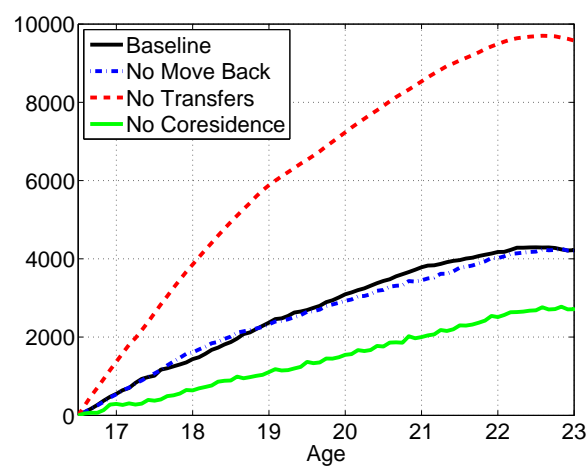

(d) Top Quartile Parental Inc Dist

Figure 10: Age profile of asset holdings, by parental income group. 


\section{A Data and Sample Selection}

The sample is drawn from the NLSY97, which is a longitudinal survey of 8,984 individuals from the cohort born between 1980 and 1984. The survey contains extensive information on labor market behavior and educational outcomes, together with detailed information on the youth's family and community background. Interviews have been conducted approximately annually since 1997.

Coresidence variables In principal, information about parental coresidence in the NLSY97 may be obtained in two ways. The simplest way is through the household roster, which records the relationship to the youth of all individuals living in his/her household at the time of the interview. However, using the household roster as the basis for coresidence information has two problems. The first is that it provides only an (approximately) annual snapshot of living arrangements. This means that using the household roster does not allow one to observe the circumstances that surround any change in living arrangements. The second problem with using the household roster is that it does not necessarily correspond to the current residence of the youth. Rather, it refers to the residence that the youth considers to be his/her primary residence. For example, a youth who has recently moved out of home may report not living with either of his parents but still report that his parents' home is his primary residence. The rosters are thus not reliable indicators of current residential status, particularly for youths whose coresidence status has recently changed.

Instead, I focus on the set of retrospective questions about monthly coresidence that were asked in rounds 2 to 6 (1998-2002). At each interview, these questions asked respondents to list each period of one month or more in which they lived separately from each of their parents. A parent is defined in the NLSY97 as a biological, step, adoptive, or foster parent.

This specific wording of the retrospective monthly coresidence questions differed slightly across waves. The main differences are that in the first 5 rounds, the respondent is given a list of each calendar month since the previous interview, and asked about his/her coresidence status in each of the months. However, in round 6 the youth is instead asked to report directly the calendar months in which changes in coresidence status took place. For each parent figure, the youth was asked the following set of questions:

\section{Rounds 2 to 5 (1998-2001)}

Now I'm going to ask you about your parents and any other people you consider to be parent figures. I will ask about each parent separately. My computer tells me that at the time of your last interview, you were living [under joint custody/[blank]] with your [mother (figure)/father (figure)] [name]. Was this information correct on [date of last interview] when we had your last interview?

[questions are then asked about updating any changes in the parent's characteristics from the previous wage]

Are you currently living with [him/her] full-time, living with [him/her] as part of a joint custody arrangement, or not living with [him/her] at all? Since [date of last interview], has there been a continuous period of one month or more when you and your [mother (figure)/father (figure)] lived in different places? If you were temporarily away at summer camp, but lived with your [mother (figure)/father (figure)] before and after that time, please include those months as months you were living with [him/her].

Since [date of last interview] what months have you lived with your [mother (figure)/father (figure)] at least some of the time? If you were temporarily away at summer camp or on vacation, but lived with your [mother (figure)/father (figure)] before and after that time, please include those months as months you were living with [him/her].

Now I'd like to ask you about parents and parent figures you weren't living with at the time of our last interview. Since [date of last interview], has there been a continuous period of one month or more when you and your [mother (figure)/father (figure)] lived in different places? Since [date of last interview] what months have you lived with your [mother (figure)/father (figure)] at least some of the time? If you were temporarily away at summer camp or on 
vacation, but lived with your [mother (figure)/father (figure)] before and after that time, please include those months as months you were living with [him/her].

\section{Round 6 (2002)}

Since [date of last interview], has there been a continuous period of one month or more when you and your [mother (figure)/father (figure)] lived in different places?

Since [respar1datefill] what month did you [resparent1firstnext] stop living with your [mother (figure)/father (figure)]? What month did you [resparent1firstnext] start living with your [mother (figure)/father (figure)]?

Was there another period of a month or more when you did not live with your [mother (figure)/father (figure)]?

[this group of questions is then repeated in a loop...]

By piecing together the responses to these coresidence questions across rounds, it is possible to reconstruct a monthly panel of parental coresidence outcomes for each respondent.

A youth is defined as living away from his parents in a given month only if he is observed to be not living with any of his living parent figures for the entire month. Conversely, a youth is defined to be living at home if he reports living with at least one parent figure at any point during the month. This implies that only spells away from home that are longer than one month's duration are considered to be valid spells in the analysis that follows, and all spells back home will be recorded as lasting at least one month.

Labor market variables Labor market variables in the NLSY97 are constructed from three sources: (i) the employer roster, which records details about each job that the youth has held; (ii) the employment event history, which is a weekly record of which employers the youth worked for in a given week; and (iii) created variables for total hours worked in the week and hourly compensation for each job in each week. The challenge is to construct monthly variables for employment, hours, and earnings from these weekly data. To do this, I define a week as falling in a particular month if the start date was on or before the 28th of the month (25th for February). This means that each month has either four or five assigned weeks.

A youth is defined as working in a particular month if he/she is recorded as working for at least one employer during at least one week in that month. Monthly earnings for working youths are defined as $52 / 12$ times average weekly hours in that month, multiplied by average hourly compensation, where the averages are taken across all jobs and all working weeks in the month. Where hours are missing but wages are available and the youth reports working full-time, 40 hours are assumed. Some youths report unrealistically high wages and hours. I deal with this misreporting by setting weekly hours above 100 to 100 , and hourly wages above $\$ 75$ to $\$ 75$, in 2007 dollars. None of the results are sensitive to the choice of these thresholds.

Asset data From round 4 onwards, information about assets and debts was only collected from youths in the first interview after they turn 20 or 25 . This means that for the relevant ages in the sample, asset information at age 20 is the most useful. However, in the first three rounds, the NLSY97 collected information on all independent youths. Having finished school, living alone or being 18 are each sufficient to be considered independent. Thus, in the first three waves asset data is available for all youths in the sample. My measure of assets includes all financial assets and vehicles less financial debts and moneys owed in respect of vehicles owned. Financial assets include businesses, pension and retirement accounts, savings accounts, checking accounts, stocks, bonds. There is some top-coding in the data: the top $2 \%$ in each category is set at the average of that group.

Tax function I use a tax function that includes three types of tax: payroll, federal and state. Payroll taxes are comprised of two parts: (i) social security tax of $6.2 \%$ of annual income up to $\$ 102,000$; and (ii) medicare levy of $1.45 \%$ of annual income with no limit. For Federal income taxes I define net income as gross income minus a standard deduction of $\$ 5,350$ and a personal exemption of $\$ 3,400$. I then use the progressive tax rates for a single with no dependents for 2007 based on this net income. I assume that state income taxes are $2.5 \%$ of gross income less a deduction for federal taxes plus another $\$ 2,500$. All 
calculations based on annual income, by multiplying the monthly income by 12 and dividing the resulting tax bill by 12 .

Sample selection The baseline sample restricts attention to youths who are never observed to participate in any type of post-secondary education (Sample A). As discussed in the main text, to address the potential concerns regarding endogeneity of the education decision, I also compare the results from this sample with those from two alternative samples that implement the restriction to low-skilled youth in different ways. Sample B selects on the basis of low test scores, which are a strong predictor of future college participation. This is done by retaining only youths who scored in the bottom quartile of the combined Armed Services Vocational Aptitude Battery, as constructed by NLS staff. The tests were administered prior to the first wave, during the NLSY97 screening process. Hence, selection in this sample is based on a purely exogenous variable, and there are no issues of endogeneity of education. Sample $\mathrm{C}$ is less restrictive than the baseline sample. Rather than dropping any youth who is ever observed to participate in post-secondary education of any type, I only drop youths who are "traditional" college participants - those youths who start college immediately after graduating from high school, or within one year of graduating. The purpose of Sample $\mathrm{C}$ is to retain youths who may attend college part-time.

The NLSY97 is itself not representative, due to an oversampling of black and Hispanic youths, as well as non-random attrition. Hence, in all estimations I use a custom set of cross-sectional weights to account for oversampling and attrition for the period 1997 to 2002. The weights are based on the characteristics of youths who are present in all six rounds (1997-2002). See http://www.nlsinfo.org/webinvestigator/custom_weights.php for information on the construction of customized weights for use with the NLSY97.

\section{B A Static Game}

In this appendix I describe the structure and Nash equilibria of a static version of the game in the full model with exogenous labor supply. Since this version of the model admits closed form solutions it is useful to demonstrate some of the key mechanisms at work in the full model.

Consider a static version of the game in which youth income is exogenous, there is no fixed cost of moving out, there are no savings, $\phi=1$ (full economies of scale) and $\gamma=1$. In this simplified version of the game the only actions are the residential choice $r \in\{0,1\}$ for the youth and the transfer amount, $T \in\left[0, I^{p}\right]$ for the parent. The wage offer of youth, $w$, the income of the parent, $I^{p}$, and the utility from independence are taken as exogenously given parameters. The payoffs in this game are given by:

$$
\begin{array}{ll}
\text { Youth: } & U^{y}=\log \left(g^{y}+(1-r) g^{p}\right)+r z \\
\text { Parent: } & U^{p}=\log \left(g^{p}\right)+\eta U^{y}
\end{array}
$$

with the following budget constraints:

$$
\begin{aligned}
g^{y}+r \chi & \leq w+T \\
g^{p}+T & \leq I^{p} \\
T \geq 0 &
\end{aligned}
$$

Note that when the youth lives at home, it is always optimal for the parent to set $g^{p}=I^{p}$. Hence, the payoffs can be written as functions of $(r, T)$ :

$$
\begin{array}{ll}
\text { Youth: } & U^{y}(r, T)=\log \left(w+T-r \chi+(1-r) I^{p}\right)+r z \\
\text { Parent: } & U^{p}(r, T)=\log \left(I^{p}-T\right)+\eta U^{y}(r, T)
\end{array}
$$

with $T=0$ when $r=0$. The assumption of $\log$ utility is not essential to obtain a closed form solution, however it simplifies the algebra.

Best Response of Parent The optimal transfer for a parent with a youth living away from home is given by:

$$
T^{*}(1)=\frac{1}{\eta+1}\left[\eta I^{p}-w+\chi\right]
$$


I assume that $w \leq \eta I^{p}+\chi$ to simplify the algebra - this assumption just says that parental income plus housing costs are much larger than the youths earnings. Note that this implies that $T^{*}(1) \geq 0$.

Best Response of Youth For a given transfer amount $T$, the youth will live away from home if $U^{y}(1, T) \geq U^{y}(0, T)$ where

$$
\begin{aligned}
U^{y}(1, T) & =\log (w+T-\chi)+z \\
U^{y}(0,0) & =\log \left(w+I^{p}\right)
\end{aligned}
$$

which generates a reservation transfer for living away from home given by:

$$
\tilde{T}=\frac{w\left(1-e^{z}\right)+I^{p}+e^{z} \chi}{e^{z}}
$$

where I have assumed $w \geq \chi$ so that it is always feasible for the youth to live away from home and $z>0$. The best response of a youth is to live away from home it $T \geq \tilde{T}$ and at home otherwise.

Nash Equilibria There is a Nash equilibrium where the youth lives away as long as $T^{*}(1) \geq \tilde{T}$ and a Nash equilibrium where the youth lives at home if $\tilde{T} \geq 0$. Since $\left.T^{*}(1)\right) \geq 0$, a Nash equilibrium will always exist, however it need not be unique. These latter Nash Equilibrium are sustained by the parent offering any transfer $T<\tilde{T}$ if the youth is to move out. This implies that if $T^{*}(1) \geq \tilde{T}$ there will be both an away equilibrium and a home equilibrium.

The payoffs for the youth and the parent in each equilibrium are given by

$$
\begin{gathered}
U^{y}(0,0)=\log \left(w+I^{p}\right) \\
U^{y}\left(1, T^{*}(1)\right)=\log \left(\frac{\eta}{\eta+1}\left(w-\chi+I^{p}\right)\right)+z \\
U^{p}(0,0)=\log \left(I^{p}\right)+\eta \log \left(w+\phi I^{p}\right) \\
U^{p}\left(1, T^{*}(1)\right)=\log \left(\frac{1}{\eta+1}\left(w-\chi+I^{p}\right)\right)+\eta \log \left(\frac{\eta}{\eta+1}\left(w-\chi+I^{p}\right)\right)+\eta z
\end{gathered}
$$

The youth prefers the away equilibrium whenever

$$
z \geq \log \left(\frac{w+I^{p}}{w-\chi+I^{p}}\right)-\log \left(\frac{\eta}{\eta+1}\right)
$$

but the parent prefers the home equilibrium if

$$
z \leq \log \left(\frac{w+I^{p}}{w-\chi+I^{p}}\right)-\log \left(\frac{\eta}{\eta+1}\right)+\frac{1}{\eta} \log \left(\frac{(\eta+1) I^{p}}{w-\chi+I^{p}}\right)
$$

If $z \geq \log \left(\frac{w+I^{p}}{w-\chi+I^{p}}\right)-\log \left(\frac{\eta}{\eta+1}\right)+\frac{1}{\eta} \log \left(\frac{(\eta+1) I^{p}}{w-\chi+I^{p}}\right)$ then both the youth and the parent prefer the away equilibrium, i.e. it Pareto-dominates the home equilibrium. If $z<\log \left(\frac{w+I^{p}}{w-\chi+I^{p}}\right)-\log \left(\frac{\eta}{\eta+1}\right)$ then both the youth and parent prefer the home equilibrium: it Pareto dominates. In both of these cases, if a timing protocol were specified then the sub-game perfect equilibrium would be the same regardless of who chose first. However, if $z$ lies in the interval between these two thresholds, there is disagreement as to which equilibrium is preferred. The youth prefers the equilibrium where he lives away and the parent prefers the equilibrium in which the youth lives at home. If the youth were to choose first, then he would choose to live away and this would be the sub-game perfect equilibrium. However if the parent were to choose first, they would choose $T^{*}=0$ and the home equilibrium would ensue. In this case the timing the timing protocol does matter. 


\section{Markov Perfect Equilibrium}

The MPE of the game can be described by a set of Bellman equations. Define $Y_{t}^{m}\left(x_{t}^{m}\right)$ and $P_{t}^{m}\left(x_{t}^{m}\right)$ as the expected discounted value along the equilibrium path at the beginning of phase $m$ of the period $t$ stage game, for the youth and the parent, respectively. The four phases of the stage game, and the corresponding state variable, $x_{t}^{m}$, are outlined in Table 11. Optimal decisions for the youth and the parent are denoted with a star $(*)$.

\begin{tabular}{clcccc}
\hline \hline Phase & Conditioning Variables & Choice & By Whom & Strategies & Value Function \\
\hline 1 & $x_{t}^{1} \equiv a_{t}, r_{t-1}, h_{t-1}, w_{t-1}, z_{t-1}$ & $w_{t}, z_{t}$ & Nature & & $Y_{t}^{1}\left(x_{t}^{1}\right), P_{t}^{1}\left(x_{t}^{1}\right)$ \\
2 & $x_{t}^{2} \equiv a_{t}, r_{t-1}, w_{t}, z_{t}$ & $r_{t}$ & Youth & $r_{t}^{*}\left(x_{t}^{2}\right)$ & $Y_{t}^{2}\left(x_{t}^{2}\right)$ \\
3 & $x_{t}^{3} \equiv a_{t}, r_{t-1}, r_{t}, w_{t}, z_{t}$ & $T_{t}, g_{t}^{p}$ & Parent & $T_{t}^{*}\left(x_{t}^{3}\right), g_{t}^{p *}\left(x_{t}^{3}\right)$ & $P_{t}^{3}\left(x_{t}^{3}\right)$ \\
4 & $x_{t}^{4} \equiv a_{t}, r_{t-1}, r_{t}, w_{t}, z_{t}, T_{t}, g_{t}^{p}$ & $h_{t}, a_{t+1}$ & Youth & $h_{t}^{*}\left(x_{t}^{4}\right), a_{t+1}^{*}\left(x_{t}^{4}\right)$ & $Y_{t}^{4}\left(x_{t}^{4}\right)$ \\
\hline \hline
\end{tabular}

Table 11: State Variables for Different Phases of the Stage Game

The value functions for the youth are given in equations (8) to (10). (8) is the expected value at the beginning of period $t$, before the current period shocks have been realized, (9) describes the discrete residence decision, taking into account the equilibrium transfer strategy of the parent and (10) is the labor supply and savings decision, which takes into account future values along the equilibrium path, summarized in $Y_{t+1}^{1}\left(x_{t+1}^{1}\right)$.

$$
\begin{aligned}
Y^{1}\left(x_{t}^{1}\right)= & \sum_{w_{t}, z_{t}} Y_{t}^{2}\left(x_{t}^{2}\right) \operatorname{Pr}\left(w_{t} \mid w_{t-1}, h_{t-1}\right) \operatorname{Pr}\left(z_{t} \mid z_{t-1}\right) \\
Y_{t}^{2}\left(x_{t}^{2}\right)= & \max _{r_{t}}\left\{Y_{t}^{4}\left(a_{t}, r_{t-1}, r_{t}, w_{t}, z_{t}, T_{t}^{*}\left(x_{t}^{3}\right), g_{t}^{p *}\left(x_{t}^{3}\right)\right)\right\} \\
Y_{t}^{4}\left(x_{t}^{4}\right)= & \max _{h_{t}, a_{t+1}}\left\{U_{t}^{y}+\beta Y_{t+1}^{1}\left(x_{t+1}^{1}\right)\right\} \\
& \text { subject to (4) }
\end{aligned}
$$

where $U_{t}^{y}=\frac{\left[c_{t}^{y(1-\phi)} G^{\phi}\right]^{1-\gamma}}{1-\gamma}-h_{t} v+r_{t} z_{t}$ and $G=g_{t}^{y}+\left(1-r_{t}\right) g_{t}^{p}$

Equations (11) to (13) describe the problem faced by a parent along the equilibrium path. Equation (11) is the expected value for the parent at the beginning of period $t$, which depends on the residence choice of the youth. Equation (12) is the optimal transfer and public good decision, which takes into account the induced labor supply and savings decisions of the youth as well as the residence decision in the following period.

$$
\begin{aligned}
& P_{t}^{1}\left(x_{t}^{1}\right)=\sum_{w_{t}, z_{t}} P_{t}^{3}\left(a_{t}, r_{t-1}, r_{t}^{*}\left(x_{t}^{2}\right), w_{t}, z_{t}\right) \operatorname{Pr}\left(w_{t} \mid w_{t-1}, h_{t-1}\right) \operatorname{Pr}\left(z_{t} \mid z_{t-1}\right) \\
& P^{3}\left(x_{t}^{3}\right)=\max _{g_{t}^{p}, T_{t}}\left\{U_{t}^{p}+\eta U_{t}^{y *}+\beta P_{t+1}^{1}\left(a_{t+1}^{*}\left(x_{t}^{4}\right), r_{t}, h_{t}^{*}\left(x_{t}^{4}\right), w_{t}, z_{t}\right)\right\}
\end{aligned}
$$

subject to $(5)$

where $U_{t}^{y *}=\frac{\left[c_{t}^{y *}\left(x_{t}^{4}\right)^{(1-\phi)} G^{* \phi}\right]^{1-\gamma}}{1-\gamma}-h_{t}^{*}\left(x_{t}^{4}\right) v+r_{t} z_{t}$ and $G^{*}=g_{t}^{y *}\left(x_{t}^{4}\right)+\left(1-r_{t}\right) g_{t}^{p}$

\section{Pareto Efficiency}

There are a number of reasons why the MPE allocations may be inefficient, relative to an environment where parents and youths can commit at $t=0$ to fully history dependent allocations. First, since parents cannot commit to transfers before youths make their coresidence decision, there may be inefficient delays 
in moving out of home, and inefficient movements back home. Second, since youths cannot commit to accept a job before parents make their transfer decisions, there may be inefficiently low transfers. Finally, a version of the Samaritan's dilemma is at work, whereby youths savings are inefficiently low because they seek to raise their marginal value of resources in order to induce higher transfers from parents.

To examine how severe are these inefficiencies, and thus the sensitivity of the results to alternative choices about how to determine allocations, I construct the Pareto-efficient frontier between parents and youths, at the estimated parameter values. I then look at the difference in welfare and allocations between the MPE and nearby points on the Pareto frontier. For a given value for the youth, $\overline{V_{0}^{y}}$, define efficient allocations to be the subset of $S$ that satisfy

$$
\overline{V_{0}^{p}}=\max _{s \in S} V_{0}^{p} \text { subject to } V_{0}^{y} \geq \overline{V_{0}^{y}}
$$

and the efficient frontier as the subset of the locus $\left(\overline{V_{0}^{y}}, \overline{V_{0}^{p}}\right)$ for which the constraint $V_{0}^{y} \geq \overline{V_{0}^{y}}$ binds. Due to the presence of altruism, there may be feasible values for $\overline{V_{0}^{y}}$ for which this constraint does not bind. In these cases, both the youth and the parent can be made better off by increasing the welfare of the youth. Clearly such allocations are not Pareto-efficient and so are not included as part of the Pareto frontier.

Note that the problem in (14) can be re-written as

$$
\max _{s \in S} \tilde{V}_{0}^{p}+(\eta+\lambda) V_{0}^{y}
$$

where $\lambda$ is a Lagrange multiplier that can be interpreted as a relative Pareto weight on the youth. Since only the combined altruism factor / Pareto weight, $\eta+\lambda$, is important for determining allocations, the assumption of efficiency alone is not sufficient for identification of $\eta$. I construct the Pareto frontier by fixing $\eta$ at its estimated value and solving the problem in (15) for different values of $\lambda$.

Game is Nearly Efficient Figure 11 shows the computed efficient frontiers $\left(\overline{V_{0}^{y}}, \overline{V_{0}^{p}}\right)$ for the four parental income groups, and the corresponding value pairs $\left(Y_{0}, P_{0}\right)$ from the MPE. This figure shows that the actual inefficiencies in the game are extremely small. Note also that in the cases where the game is efficient, the MPE lies on a point on the Pareto frontier that puts essentially no direct weight on the utility of the youth i.e. $\lambda \approx 0$. If the game were indeed to generate efficient allocations, then this would necessarily be the case. To see why, it is useful to compare equation (6) that determines transfers for youths living away from home in the game, with the corresponding equation in the efficient allocations:

$$
\begin{aligned}
\tilde{\phi}\left(c_{j t}^{p}+c_{j t}^{g}\right)^{-\gamma} & \leq(\eta+\lambda) \frac{\partial V_{t}^{y}}{\partial a_{t}}+\beta \frac{\partial E\left[\tilde{V}_{t+1}^{p}\right]}{\partial a_{t}} \\
T_{j t} & =0 \text { if inequality is strict }
\end{aligned}
$$

It is clear that if the value functions in (6) and (16) are to coincide, then the only way that the game could generate an efficient level of transfers is if $\lambda=0$.

Why Prefer the Game as the Baseline? If the inefficiencies generated by the game are so small (and the game is more difficult to compute), then why focus on the MPE, which requires additional assumptions about timing and commitment, as the preferred model of behavior? There are at least four reasons. First, the game is intuitive and generates some outcomes that appeal to introspection about the nature of parent-youth interactions. For example, parents may make substantial transfers even though they would prefer the youth to live at home. Also, parents can not control the labor supply and savings of non-resident youths directly, but can only partially influence them through their choice of financial transfers. If a youth has a strong enough preference for independence, he will move out regardless of the parent's actions.

Second, the particular specification of the game implicitly assumes that parents and youths cannot commit to future decisions. This seems more in touch with reality than the assumption implicit in the Pareto-efficient allocations - that parents and youths can commit at age 16 to a full set of contingent allocation rules for coresidence, labor supply, consumption and savings. 


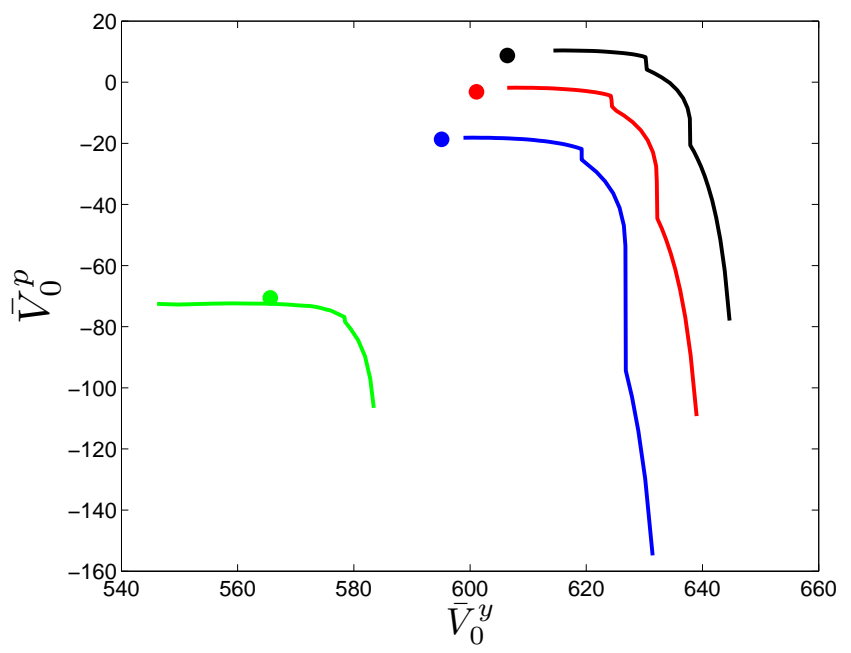

Figure 11: Pareto frontiers for each quartile of the parental income distribution. Values for parents include both direct utility and indirect utility from altruism.

Third, there is an important advantage of the game in terms of identification of structural parameters. Under the assumption of Pareto-efficiency, only the combined Pareto-weight and altruism factor, $\eta+\lambda$, is identified, which makes it difficult to use the model to do policy experiments and examine counterfactual exercises. Only a locus of possible counterfactual outcomes are identified, indexed by how the estimated value for $\eta+\lambda$ is split between $\eta$ and $\lambda$. The implicit bargaining weight, $\lambda$, may respond endogenously to changes in the environment, an issue which is not of concern when using the game to determine allocations. ${ }^{63}$

Finally, it is useful to be able to connect with the existing literature on parent-youth interactions, which has predominantly used a non-cooperative game-theoretic approach to model behavior. Games with a similar structure to the one analyzed here are used in Rosenzweig and Wolpin (1993),Rosenzweig and Wolpin (1994), Ermisch and Di Salvo (1997) and Becker et al. (2008). However, note that in contrast to the model in Rosenzweig and Wolpin (1993) and Rosenzweig and Wolpin (1994), I specify that it is the youth, rather than the parent who makes the coresidence decision. An exception is the static model estimated by McElroy (1985), which assumes that cooperative Nash bargaining determines coresidence outcomes.

\section{E Numerical Solution of the Model}

The model is solved by backward induction from the terminal value functions that are described in Section 3. The wage offer distribution is discretized to a 9 point distribution, equally spaced in logs between $\$ 450$ and $\$ 8000$. The lower point is chosen to be $90 \%$ of the unemployment benefit and the upper point is the 97th percentile of the observed wage distribution. The distribution of $\log$ preference shocks, $\log (z)$, is discretized to a 7 point stationary Markov chain with second moments defined by $\rho_{z}$ and $\sigma_{z}^{2}$. The grids are then transformed to yield a distribution with mean $\alpha_{z}+(t-1) \beta_{z}$ in levels. Value functions and decision rules are solved on a grid with 16 points for assets and 7 points for public consumption inside

\footnotetext{
${ }^{63}$ If the efficient allocations were implemented through some decentralized system, then $\lambda$ would reflect the implicit bargaining power given to the youth and hence the resulting point on the Pareto frontier. However, depending on the details of the decentralization, changes in the environment may change the effective value of $\lambda$, leading to a different point on the Pareto frontier being chosen. In the dynamic game, the assumption about the timing of actions pins down the effective bargaining power of youths and parents.
} 
the parental home. Linear interpolation (bi-linear interpolation for two-dimensional problems) is used to evaluate values between grid points. The asset decision for the youth is solved using a golden search with multiple starting values at each point in the state space. The discrete choices (coresidence, labor supply) are solved by interpolating the choice-specific value functions at the relevant stage of the game.

Minimization of the simulated minimum distance objective function is performed using a trust-region method for non-smooth non-linear least squares functions developed by Zhange and Scheinberg (2009). The algorithm works by forming a sequence of smooth approximation to each of the moment conditions being targeted. I use multiple restarts from many different starting points in the parameter space to ensure that a global maximum is found.

\section{F Calibrating $\phi$ from Equivalence Scales}

Consider the problem of a one-person household with Cobb-Douglas utility over two consumption goods, $c$ and $g$, and income $I$ :

$$
\begin{gathered}
\max _{c, g} g^{\phi} c^{1-\phi} \\
\text { subject to } \\
g+c=I
\end{gathered}
$$

Such a household sets $g^{*}=\phi I$ and $c^{*}=(1-\phi) I$ and obtains an indirect utility function $V^{1}(I)=$ $\phi^{\phi}(1-\phi)^{1-\phi} y$.

Now consider a two-person household (whom I will denote as $p$ and $y$ ) with total income $I$. With a unitary model for decision making in the household, and equal weights on the two members, the household solves the problem:

$$
\begin{array}{r}
\max _{c, g} g^{\phi} c_{y}^{1-\phi}+g^{\phi} c_{p}^{1-\phi} \\
\text { subject to } \\
g+c_{y}+c_{p}=I
\end{array}
$$

The solution to this problem is to set $g=\frac{1+\phi}{2} I$ and $c_{y}=c_{p}=\frac{1-\phi}{2} I$. The indirect utility function for each of the two household members is $V^{2}(I)=\left(\frac{1+\phi}{2}\right)^{\phi}\left(\frac{1-\phi}{2}\right)^{1-\phi} I$.

The value of $\phi$ that is consistent with an equivalence scale $e$ is defined as the $\phi$ such that $V^{1}(I)=$ $V^{2}(I e)$. This gives

$$
e(\phi)=2\left(\frac{\phi}{1+\phi}\right)^{\phi}
$$

Note that $e(0)=2$ so that with no economies of scale, income needs to be doubled when moving from a one-person to a two person households in order to keep welfare constant. Similarly, $e(1)=1$ so that with full economies of scale, no additional income is required to keep welfare constant when a second member is added to the household.

I consider the additional income required when adding a second adult member to a two-adult household that is implied by three commonly used equivalence scales. I focus on the addition of second adult, rather than a child, because 17 to 23 year-olds are better thought of as adults rather than children for consumption purposes. The OECD Equivalence Scale implies $e=1.41$, the OECD-Modified Equivalence Scale implies $e=1.33$ and the Square Root Scale implies $e=1.22$. Using the formula above that relates $e$ to $\phi$, these numbers imply a value for $\phi$ between 0.20 and 0.42 . I choose the approximate midpoint, 0.3 . 